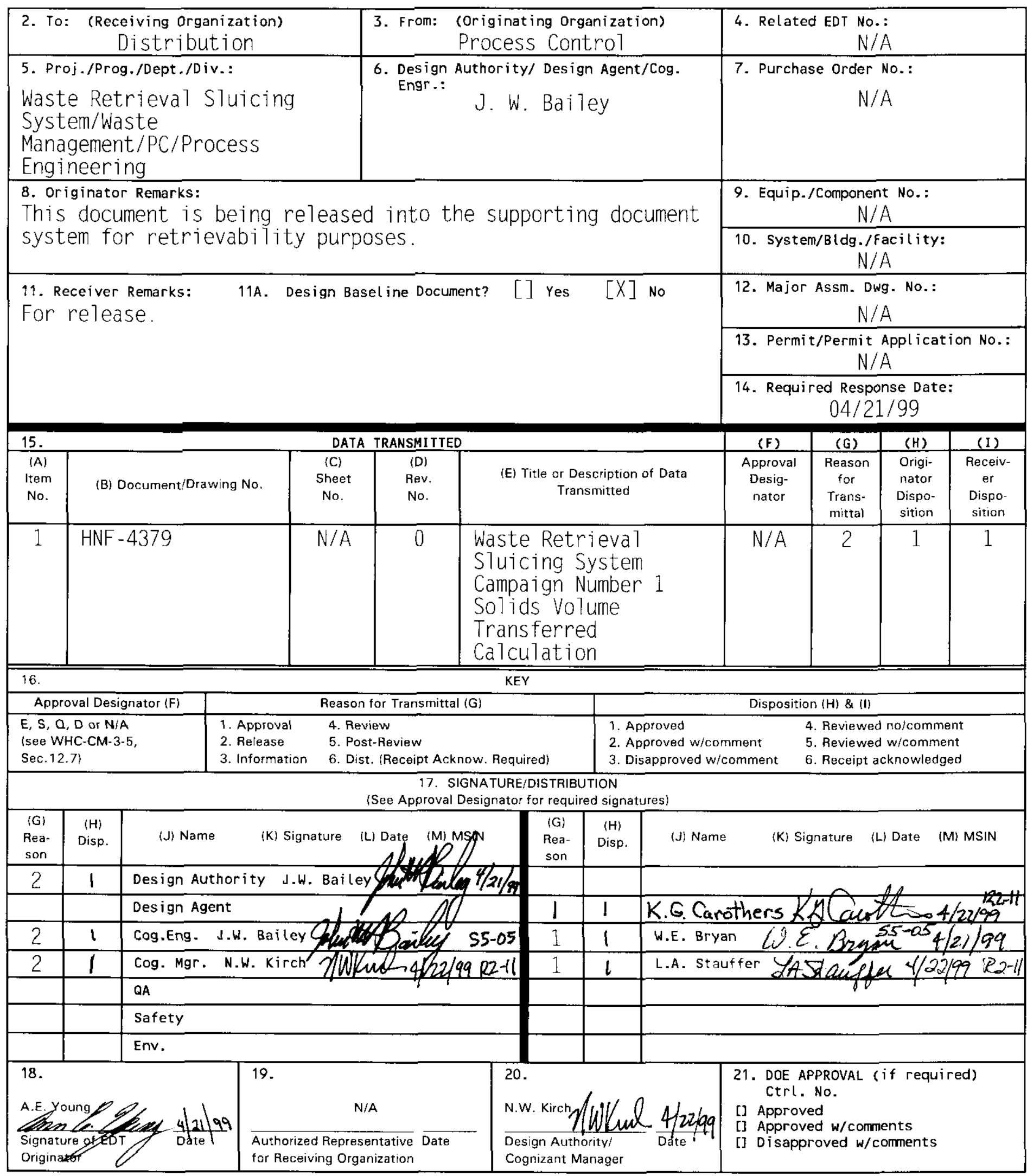

BD-7400-172-2 (05/96) GEF097 


\section{Waste Retrieval Sluicing System Campaign Number 1 Solids Volume Transferred Calculation}

J. W. Bailey

Lockheed Martin Hanford, Corp., Richland, WA 99352

U.S. Department of Energy Contract DE-AC06-96RL13200

EDT/ECN: EDT-611462 UC: 2070

Org Code: $74 B 50 \quad$ CACN/COA: 101982/EF00

B\&R Code: EW 3120074 Total Pages: 35

Key Words: Waste Retrieval Sluicing System, WRSS. Campaign 1. Solids, Volume, Transfer, Calculation. Retrieval Project, Characterization.

Retrieval

Abstract: $N / A$

ENRAF is a product of ENRAF Corporation of the Netherlands

EXCEL is a product of Microsoft Corporation

TRADEMARK DISCLAIMER. Reference herein to any specific commercial product, process, or service by trade name, trademark, manufacturer, or otherwise, does not necessarily constitute or imply its endorsement, recommendation, or favoring by the United States Government or any agency thereof or its contractors or subcontractors.

Printed in the United States of America. To obtain copies of this document, contact: Document Control Services, P.O. Box 950, Mailstop H6-08, Richland WA 99352, Phone (509) 372-2420;

Fax (509) 376-4989.
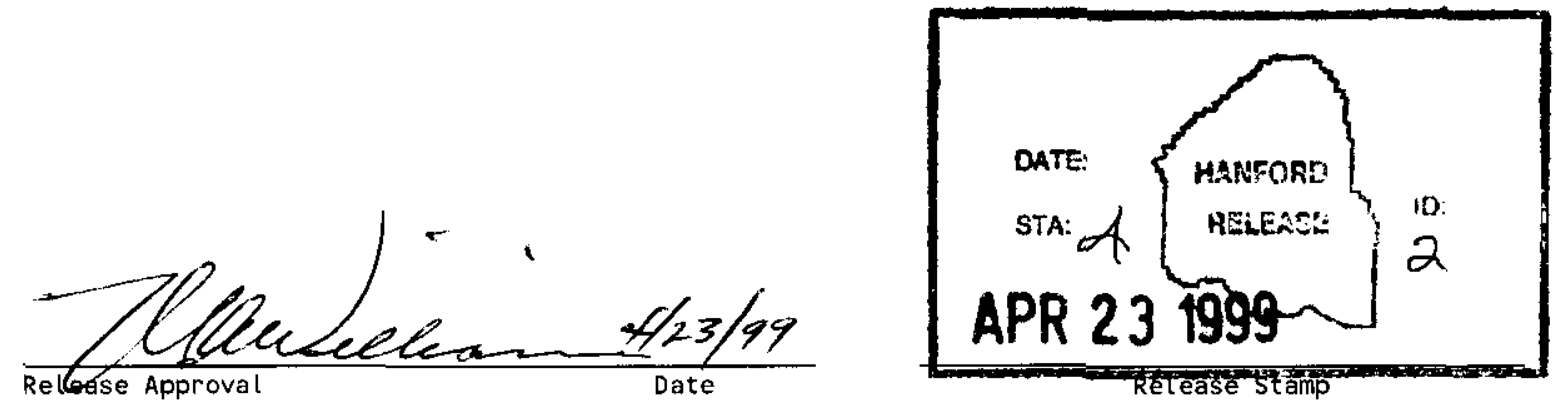

Approved for Public Release 


\section{OBJECTIVE / PURPOSE}

This calculation has been prepared to document the volume of sludge removed from tank 241-C-106 during Waste Retrieval Sluicing System (WRSS) Sluicing Campaign \#1. This calculation will be updated, if necessary, to incorporate new data.

This calculation supports the declaration of completion of WRSS Campaign \# 1 and, as such, is also the documentation for completion of Performance Agreement TWR 1.2. 1, C-106 Sluicing Performance Expectations. It documents the performance of all the appropriate tank 241-C-106 mass transfer verifications, evaluations, and appropriate adjustments discussed in HNF-SD-WM-PROC-021, Chapter 23, "Process Engineering Calculations for Tank 241-C-106 Sluicing and Retrieval".

\section{RESULTS}

The sludge volume removed from tank $241-\mathrm{C}-106$ is $\mathbf{2 5 . 4}$ inches or $\mathbf{6 9 , 8 5 0}$ gallons, including an uncertainty of +4.0 to -4.8 inches $(+11,000$ to $-13,200$ gallons $)$

The above value is based on the following volume calculations.

1. MASS FLOW METER TRANSFER VOLUME $($ CORRECTED) $=\mathbf{2 6 . 3 2}$ inches or $\mathbf{7 2 , 3 8 0}$ gallons.

SETTLED \& DISSOLVED SOLIDS VOLUME $=\mathbf{2 5 . 1 2}$ inches or $\mathbf{6 9 , 0 8 0}$ gallons

a. 241-AY-102 Final Settled Solids Volume $=\quad$ 14.22" or 39,100 gallons

b. Dissolved Solids Volume $=\quad$ 10.9" or 29,980 gallons.

3. THE ABOVE CALCULATED VOLUME IS BASED ON A WEIGHTED AVERAGE

OF THE VOLUMES DETERMINED BY THE MASS FLOW METER AND SETTLED/DISSOLVED VOLUME APPROACHES. THE WEIGHTING IS INVERSELY PROPORTIONAL TO THE UNCERTAINTY RANGES ASSOCIATED WITH EACH OF THESE CALCULATION APPROACHES

4. THE UNCERTAINTY RANGES ARE DEVELOPED IN THE UNCERTAINTY SECTION OF THIS CALCULATION.

For details of the calculation of each of these values refer to the following sections. 
WRSS CAMPAIGN \#1 SOLIDS VOLUME

TRANSFERRED CALCULATION
HNF-4379, Revision 0

Page 2 of 34

\section{METHOD OF ANALYSIS}

This calculation uses two methods to evaluate the volume of sludge removed from tank 241-C-106. This increases the level of confidence in the sludge volume value determined by this calculation. The two methods used for the calculation are:

1. Corrected mass flow meter data

2. The sum of settled solids and dissolved solids

The mass flow meter data was corrected for errors in the assumed average solids free liquid density for each of the sluicing batches, as required. These corrections are discussed in more detail in the mass flow meter calculation section of this document. The resulting sludge volume value was then compared to the alternate calculation approach value. The settled solids and dissolved solids calculations are discussed in detail in the calculation section of this document. The final calculated value is a weighted average of these two alternative calculation values. The development of the volume uncertainty estimates is discussed in detail in the uncertainty section of this document.

The sludge transferred volumes are reported in both inches (of waste in the tank) and gallons. The inch units were selected for convenient comparison to the Performance Agreement value of two feet while providing improved accuracy. The gallon conversions were provided to allow convenient use in other calculations.

The uses of the input data are discussed in the following paragraphs.

The supernate density data (determined by the densitometer) has several uses. It is used in conjunction with grab sample density values to adjust the mass flow meter system solids free liquid density that is input to the DAS system before the start of the sluicing batch, if necessary. It is also used in conjunction with grab sample density values to determine the volume of solids dissolved by the WRSS sluicing operations.

The densitometer solids levels are used to project the final settled solids volumes in tank 241-AY-102.

The dissolved solids volume is calculated and added to the settled solids volume, above, to produce the alternate calculation of the volume of material removed from tank 241-C-106 to compare to the mass flow meter volume calculation.

Several other sources of data are reviewed to provide indications which support the above calculation inputs or to identify potential problems which require additional evaluation.

It should be noted that the ENRAF ${ }^{\mathrm{TM}}$ densitometer (ENRAF is a product of ENRAF corporation of the Netherlands) material balance discussed in HNF-SD-WM-PROC-021 could not be performed for the reasons discussed below. Recommendations related to correcting the densitometer data problems to make the instrument density profiles useable for future WRSS process control are provided in the Conclusions and Recommendation section of this calculation. 


\section{INPUT DATA}

Several sources of data are used to develop the volume of sludge removed from tank 241-C-106 by WRSS operations. The data sources include the following:

\section{PRIMARY}

1. Mass flow meter (UE-0621) located in the tank 241-AY-102 02A pit

\section{SECONDARY - VERIFICATION DATA SOURCES}

2. Supernate density data from both the ENRAF densitometer (WST-DIT-602A) and post batch grab sample analytical results from preliminary analysis reports

3. Tank 241-AY-102 solids level data from the ENRAF densitometer (WST-DIT-602A)

4. Dissolved solids volume developed from ENRAF densitometer (WST-DIT-602A) data and from post batch grab sample analytical results from preliminary analysis reports

The WRSS Process Control Plan, HNF-SD-WM-PCP-013, Revision IA, identifies the ENRAF densitometer as the primary solids mass determination instrument during the first sluicing campaign because the solids loading was expected to be below $10 \%$. It indicates that the mass flow meter was to be the primary instrument for subsequent campaigns. Because of problems encountered with the densitometer data, discussed below, and the fact that the slurry solids loading were frequently above the $10 \%$ during the first campaign, the mass flow meter has been used as the primary solids transfer instrument for the first campaign.

\section{CALCULATIONS}

The following calculations are broken down into four sections: 1) the mass flow meter transfer volume calculation, 2) the settled solids volume calculation, 3) the dissolved solids volume calculation, and 4) other related process control data.

I. MASS FLOW METER TRANSFER VOLUME CALCULATION - The sludge volume transferred based on the mass flow meter data from each of the sluicing batches is presented below. Corrections to these values, where appropriate, are also included in this section of the calculation.

\begin{tabular}{llll} 
WRSS Batch & \multicolumn{2}{l}{ Transferred Volume } & Input Liquid Sp \\
& (Inches) & (Gallons) & \\
Batch 1.1.1 & $2.89^{\prime \prime}$ & $(7,958 \mathrm{gal})$ & 1.054 \\
Proc. Test Phase I & $0.84 "$ & $(2,322 \mathrm{gal})$. & 1.037
\end{tabular}


WRSS CAMPAIGN \#1 SOLIDS VOLUME

TRANSFERRED CALCULATION
HNF-4379, Revision 0

Page 4 of 34

1.061

1.095

Because the mass flow meter solids transfer volume values are calculated using a solids free liquid specific gravity value which must be estimated in advance, it is appropriate to check this value after each sluicing operation. If it is determined that the input values diverge significantly from analytical and densitometer data, it is appropriate to make adjustments to the mass flow meter solids transfer values.

The estimation of the average carrier fluid specific gravity value for a sluicing batch is a non-trivial task for several reasons.

1. The mixing of the original tank 241-C-106 and tank 241-AY-102 liquid volumes of significantly different specific gravities must be accounted for.

2. The volume of solids that will be dissolved by the sluicing operation must be estimated.

3. The duration and different steps of the sluicing operation must be predicted.

The review of the solids free carrier fluid specific gravity $(\mathrm{SpG}$ ) inputs for the first four sluicing batches resulted in a decision to adjust the mass flow meter solids transter values for process test phases II and III. The adjustment calculations are provided below.

The Batch 1.1.1 SpG input value was not adjusted. It can be seen that the input SpG value of 1.054 was significantly higher than the post batch tank 24l-AY-102 grab sample SpG value of 1.025 . The average tank 241-AY-102 SpG approach to calculating the appropriate carrier fluid density input value isn't applicable to this first sluicing batch. Because the batch was short, the carrier fluid density was most influenced by the bulk fluid density of the waste present in tank 241-C-106 before the start of sluicing operations. The tank 241-C-106 liquid SpG was much higher than that present in tank 241-AY-102. Therefore, it was decided to make no adjustment to the mass flow meter value. It should be noted that any adjustment of the Batch 1.1.1 mass flow meter transfer calculation would have produced a higher calculated volume for this batch

The phase I process test SpG input was so close to the average of the pre- and post batch values that no adjustment was warranted.

A. Process Test Phase II Mass Flow Meter Adjustment Calculation - The mass flow meter calculates the percent solids being transferred in the slurry line and integrates this value over time to determine the mass of solids transferred. The following equation is used by the mass flow meter to perform this calculation:

$$
\mathrm{Co}=100[\mathrm{Dp}(\mathrm{Dm} \cdots \mathrm{Df})] /[\mathrm{Dm}(\mathrm{Dp}-\mathrm{Df})]
$$


WRSS CAMPAIGN \#I SOLIDS VOLUME

TRANSFERRED CALCULATION
HNF-4379, Revision 0

Page 5 of 34

Where: $\quad$ Co is the slurry percent solids

$\mathrm{Dp} \quad$ is the density of the solid particles

$\mathrm{Dm}$ is the density of the solid / fluid slurry

Df is the density of the carrier fluid

All of the values for the variable used in this equation are known for the phase II process test.

$$
\begin{array}{ll}
\mathrm{Co}=8.92 \% & \begin{array}{l}
\text { (This value is the average from the DAS } 10 \mathrm{~min} \text { frequency } \\
\text { percent solids data) }
\end{array} \\
\mathrm{Dp}=2.61 \mathrm{SpG} \quad \text { (This value is derived from core and grab sample data) } \\
\mathrm{Dm}=1.12 \mathrm{SpG} \quad \text { (Average slurry density (DI-0621 A) from 13:51:40-20:24:10) } \\
\mathrm{Df}=1.061 \mathrm{SpG} \quad \begin{array}{l}
\text { (This is the estimated solids free liquid density value input to } \\
\text { the DAS) }
\end{array}
\end{array}
$$

A corrected average carrier fluid density is next calculated by averaging the pre- and post process test phase II carrier fluid densities. The post sluicing value is $1.061 \mathrm{SpG}$ which comes from the average of the grab sample liquid analyses. The pre-sluicing value is calculated by averaging the lowest densitometer density values taken between $12 / 18 / 98$ and 3/4/99 and is $1.052 \mathrm{SpG}$. The post process test phase I grab sample analysis density value of 1.080 was determined to be highly questionable based on subsequent SpG data and was therefore, not used for this calculation. The resulting corrected carrier fluid density for process test phase II is:

$$
(1.052+1.061) / 2=1.057 \mathrm{SpG}
$$

By substituting the corrected average fluid density values into the Co calculation equation a corrected average percent solids value for the phase II process test slurry transfer can be calculated.

$$
\begin{aligned}
& \mathrm{Co}=100(2.61(1.12-1.057)) /(1.12(2.61-1.057)) \\
& \mathrm{Co}=9.45 \%
\end{aligned}
$$

The correction factor for adjusting the mass flow meter transfer numbers is then determined by dividing the corrected percent solids value by the original value:

$$
\text { Correction Factor }=9.45 / 8.92=1.059
$$

Applying this factor to the original transfer volume calculation produces the corrected transfer volume for process test phase II

$$
8.20 " \times 1.059=\mathbf{8 . 6 8} "(\mathbf{2 3 , 8 7 0} \text { gallons })
$$


B. Process Test Phase III Mass Flow Meter Adjustment Calculation - The process test phase III mass flow meter calculation is adjusted using exactly the same technique discussed for the phase II process test. The adjustment calculations are presented below

Again all the values in the mass flow equation are known.

$$
\begin{array}{ll}
\mathrm{Co}=3.39 \% & \begin{array}{l}
\text { (This value is the average from the DAS } 10 \text { second frequency } \\
\text { percent solids data) }
\end{array} \\
\mathrm{Dp}=2.61 \mathrm{SpG} & \begin{array}{l}
\text { (This value is derived from core and grab sample data) } \\
\mathrm{Dm}=1.129 \mathrm{SpG}
\end{array} \\
\begin{array}{l}
\text { (Average slurry density (DI-0621 A) from } 11: 12: 55- \\
18: 27: 55)
\end{array} \\
\mathrm{Df}=1.095 \mathrm{SpG} \quad \begin{array}{l}
\text { (This is the estimated solids free liquid density value input to } \\
\text { the DAS) }
\end{array}
\end{array}
$$

A corrected average carrier fluid density is next calculated by averaging the pre- and post process test phase III carrier fluid densities. The post sluicing value is $1.095 \mathrm{SpG}$ which comes from the average of the grab sample liquid analyses. The pre-sluicing value comes from the average of the grab sample liquid analyses taken after the phase II test sluicing operations and is $1.061 \mathrm{SpG}$. The resulting corrected carrier fluid density for process test phase II is:

$$
(1.061+1.095) / 2=1.078 \mathrm{SpG}
$$

This corrected carrier fluid density is now substituted into the percent solids equation and solved for the adjusted solids percentage for the phase 11 process test slurry transfer.

$$
\begin{aligned}
& \mathrm{Co}=100(2.61(1.129-1.078)) /(1.129(2.61-1.078)) \\
& \mathrm{Co}=7.69 \%
\end{aligned}
$$

The correction factor for adjusting the phase III test mass flow meter transfer numbers is then determined by dividing the corrected percent solids value by the original value:

$$
\text { Correction Factor }=7.69 / 3.39=2.27
$$

Applying this factor to the original transfer volume calculation produces the corrected transfer volume for process test phase III

$$
6.87 " \times 2.27=15.59 "(42,870 \text { gallons })
$$

The corrected mass flow meter solids transfer volume can now be calculated by substituting the above corrected values into the transfer summary presented at the beginning of this section. 


\begin{tabular}{|c|c|c|c|}
\hline \multirow[t]{2}{*}{ WRSS Batch } & \multicolumn{2}{|c|}{ Transferred Volume } & \multirow{2}{*}{$\frac{\text { Corrected Input Liquid }}{(\mathrm{SpG})}$} \\
\hline & (inches) & (gallons) & \\
\hline Batch 1.1.1 & $2.89 "$ & $(7,958$ gal. $)$ & No Change \\
\hline Proc. Test Phase I & $0.84 "$ & $(2,322$ gal. $)$ & No Change \\
\hline Proc. Test Phase II & $8.68^{\prime \prime}$ & $(23,870$ gal. $)$ & 1.057 \\
\hline Proc. Test Phase IIl & $15.59^{\prime \prime}$ & $(42,870$ gal. $)$ & 1.078 \\
\hline
\end{tabular}

\section{Corrected Subtotal 28.00" (77,000 gal.)}

To account for solids recycled to tank $24 \mathrm{l}-\mathrm{C}-106$ by the sluice stream a $6 \%$ correction factor has been established by prior analysis, reference HNF-SD-WM-PCP-013, Revision IA, section 4.1.4, Tank 241-C-106 Mass Transfer Control. Applying this correction to the above corrected mass flow meter solids transferred volume gives the final mass flow meter solids transfer volume.

\section{Correction for recycled solids $-28.00 "$ X $0.94=\mathbf{2 6 . 3 2}$ inches $\mathbf{( 7 2 , 3 8 0}$ gallons $)$}

II. 241-AY-102 SETTLED SOLIDS VOLUME CALCULATION - The settled solids volume calculated below is added to the dissolved solids volume, calculated in Section IIl, to produce an alternative approach solids volume calculation.

The densitometer solids (sediment) levels have been interpreted to project the final settled solids volume transferred into tank 24l-AY-102. The initial solids level data from sluicing batches can not be used directly because settling or compacting of the solids occurs over a several month period after the initial settling.

The purpose of the calculations below is to project the compacted settled solids volume for the solids transferred into tank 241-AY-102. For the purposes of this calculation, compacted solids are defined as solids at the same density or compaction level as the tank 241-C-106 solids before the start of sluicing operations.

Based on the densitometer results experienced to date the solids settling process occurs in four phases. The first is the buildup of solids level to a maximum level occurring in the five to seven days immediately after the sluicing operation. The second phase is fast settling for a one to eight day period, after the maximum value is achieved. The third phase is medium rate settling for a period of six to seven days following the fast settling rate period. The fourth and final phase is slow settling for two to three months following the medium rate settling period

The data used in the calculations below is contained in Attachment 1 to this calculation.

A. Settling Baseline - To support calculating the final volume of settled solids, the densitometer data from WRSS operations between November 15, 1998 and March 4, 1999 is used to establish a baseline for the settling response of the transferred waste. The baseline evaluation period 
includes solids transferred by WRSS Batch 1.1.1 and process test phase I sluicing. This baseline is modified, as required, based on the actual settling results from the subsequent batches.

- Pre-Batch Solids Level

Densitometer R
$9.11 "$
$12.90^{\prime \prime}$
$12.20^{\prime \prime}$
$11.93 "$
$12.11 "$
$12.28^{\prime \prime}$

Date

$(12 / 19 / 98)$

Based on the above densitometer solids level data, the following solids level baseline is calculated:

1. Solids Level Increase (12.90-9.11)

Base Value

2. Medium Settling Period Level Decrease (12.90-12.2)

3.79 "

$0.70^{\prime \prime}$

3. Process Test Correction $(12.28-12.11)$

0.17

4. Long-Term Settling Level Decrease $(12.90-11.93)$

$0.97^{\prime \prime}$

5. Long-Term Settling Decrease - Corrected $(.97+.17)$

1.14"

The Batch 1.1.1 and process test phase I final settled solids volume calculation follows:

$$
3.79 "-0.97^{\prime \prime}=\underline{\mathbf{2 . 8 2}}
$$

B. Process Test Phase II Solids Volume Transferred Calculation - The densitometer reading associated with the phase 11 testing operations follow:

- Pre-Process Test Phase Il Solids Level

- Max. Post Process Test Phase II Solids Level

- Post Medium Rate Settling Solids Level $11.93^{\prime \prime}(3 / 4 / 99)$

$20.16^{\prime \prime}(3 / 15 / 99)$

$18.05^{\prime \prime}(3 / 25 / 99)$

The medium rate settling solids level decrease, 2.11" (calculated from the above data), is a larger percentage decrease than would be calculated based on the baseline values from $\mathrm{A}$, above. For this reason an alternative method of calculating the final settled solids volume had to be developed. The alternative approach assumes that the ratio of the medium rate settling volume reduction and the final settled solids volume reduction will be the same as the ratio determined for these values from the baseline period. It also assumes that the 18.05" densitometer reading, taken just before the start of process test phase III sluicing, equates to the end of the medium settling rate period. The latter assumption is supported by a comparison of the duration of the fast and medium settling rate periods from the baseline evaluation

The process test phase II final settled solids volume calculation follows

1. Initial Solids Level Increase (20.16" - 11.93") =

$8.23 "$

2. Medium Rate Settling Solids Lev. Decrease (20.16-18.05) = 2.11" 
WRSS CAMPAIGN \#1 SOLIDS VOLUME

TRANSFERRED CALCULATION
HNF-4379, Revision 0

Page 9 of 34

3. Final Settled Solids Level (2.1 " X (1.14"/0.70")) . 34."

4. Solids Volume Transferred $\left(8.23 "-3.44^{\prime \prime}\right)=\underline{4.79 "}$

C. Process Test Phase III Solids Volume Transferred Calculation - The densitometer reading associated with the phase III testing operations follows:

- Pre-Process Test Phase III Solids Level

$18.05 "(3 / 25 / 99)$

- Max. Post Process Test Phase IIl Solids Level

$29.40 "(4 / 5 / 99)$

The solids volume transferred by process test phase III is calculated assuming the ratio of the maximum solids level change and the final solids level volume transferred established by the above phase II transfer calculation are applicable to this transfer. The solids volume transferred calculation follows:

1. Process Test Phase III Solids Level Increase $(29.4 "-18.05 ")=11.35 "$

2. Solids Volume Transferred (11.35"X $(4.79 / 8.23)=\underline{\mathbf{6 . 6 1} "}$

D. Total Solids Volume Transferred During Campaign \# I Calculation - The calculation of the total campaign \#1 solids transfer sums the values from the A., B. \& C. calculations above.

$$
2.82 "+4.79 "+6.61 "=\underline{14.22 "}
$$

III. DISSOLVED SOLIDS VOLUME CALCULATION - The dissolved solids volume calculated below is added to the settled solids volume, calculated in Section II, to produce an alternative approach solids volume calculation.

The volume of solids dissolved by WRSS sluicing operations is calculated by determining the change in solids-free liquid density between that which would be expected with no solids dissolution and the actual solids-free liquid density determined from grab sample analysis.

The bulk liquid density expected for the WRSS system for different solids volume transfers has been calculated by Mr. K. G. Carothers using an EXCEL ${ }^{\text {TM }}$ (EXCEL is a product of Microsoft Corporation) spreadsheet, "WRSS Sample Data". This spreadsheet calculates both the liquid density and chemical composition that would be expected if the tank 24l-AY-102 liquid, the tank 241-C-106 liquid, and interstitial liquid are combined with no solids dissolution. The spreadsheet $\mathrm{SpG}$ value for a two foot solids transfer to tank 24 l-AY-102 is 1.050 .

The post process test phase III grab sample analytical result $\mathrm{SpG}$ average is 1.095 giving a density change due to solids dissolution of 0.045 or $0.045 \mathrm{~g} / \mathrm{cc}$. Applying the conversion from $\mathrm{g} / \mathrm{cc}$ to $\mathrm{lb} . /$ gallon (8.32) gives a $0.3744 \mathrm{lb}$./gallon density change.

The tank 241-AY-102 liquid level (4/6/99) is 170.7" minus the settled solids volume of approximately 28" (from the rounded off April 6, 1999 densitometer sediment level determination). This gives a liquid volume of 142.7 ". Added to this is half the interstitial liquid contained in the 
solids settled in tank 241-AY-102 since WRSS sluicing operations began. Only one half the volume is used to account for the fact that the actual interstitial liquid varies in dissolved solids content depending on which sluicing batch deposited the solids. Because the last two sluicing batches were significantly larger than the first two this approximation should provide a conservative volume of interstitial liquid at the above change in liquid density value. See calculations below:

0.78 (vol.\% interstitial liq.) $[28 "($ solids lev.) $-9.11 "$ (orig. solids lev.) $] / 2=7.4 "$

Combining the two liquid volumes $(142.7 "+7.4 ")=150.1 "$

Converting this to gallons $(150.1$ " X $2750 \mathrm{gal} . / \mathrm{in})=412,$.775 gallons

Multiplying by the density change gives $(412,775 \times 0.3744)=154,540 \mathrm{lb}$.

Dividing by the pound solids per inch of sludge value, $14,200 \mathrm{lb}$./in (derived from data in the PCP, HNF-SD-WM-PCP-013) for tank 241-C-106 solids gives the equivalent tank 241-C-106 sludge volume currently dissolved in the tank $24 \mathrm{l}-\mathrm{AY}-102$ supernate $(154,540 \mathrm{lb} / 14,200 \mathrm{lb}$./in. $)=10.9$ inches

IV. FINAL SOLIDS VOLUME TRANSFERRED DETERMINATION - One method of combining the two calculated values to produce a final solids volume transferred calculation value is to perform a weighted average. The two calculated values have been weighted using an inverse proportionality relationship of the uncertainties applicable to each of the values calculated in the Calculation Uncertainty Estimates section, below. It was felt that this would produce an average with a lower uncertainty.

A. The transferred volume from the mass flow meter is 26.31 inches or 72,350 gallons. The uncertainty for this value is \pm 10.2 inches.

B. The transferred volume from the settled and dissolved solids calculation is $(10.9$ " +14.22 " $)=$ 25.12 inches or 69,080 gallons. The uncertainty for this value is +4.0 to -4.8 inches.

The maximum uncertainty ranges for the two values are $(10.2 "+10.2 ") 20.4$ " and $(4.0 "+$ $\left.4.8^{\prime \prime}\right)=8.8$ ", respectively. The two weighting factors for the A and $\mathrm{B}$ value uncertainty are:
A. $100 \%(20.4 /(20.4+8.8))=69.9 \%$
B. $100 \%(8.8 /(20.4+8.8))=30.1 \%$.

Applying the A weighting factor to the B volume calculation $-0.699(25.12$ ") $=17.5$ inches Applying the B weighting factor to the A volume calculation $-0.301(26.32$ ") $=7.9$ inches

The inversely proportionally weighted average value of the final solids volume transferred calculation value is $17.5^{\prime \prime}+7.9 "=\mathbf{2 5 . 4}$ inches. 
V. OTHER RELATED PROCESS CONTROL DATA - This section is broken down into a section discussing other process control data which support the above solids volume calculated values and a sub-section on process control data which is inconclusive or anomalous.

A. Other Supporting Process Control Data - Additional support for the 25.4 inch solids volume transfer comes from several instruments including: 1) the tank 241-C-106 thermocouples, 2) the tank 241-AY-102 MIT thermocouples, and 3) the tank 241-AY-102 MIT validation probe temperature profile.

1. The tank 241-C-106 riser R-14 thermocouple number three - This thermocouple should have been exposed to the tank supernate after process test phase II Transfer of one foot of waste from the tank should have reduced the solids level in the center portion of the tank by 15.95 inches due to the five foot "No Sluice Zone" around the perimeter of the tank. The original average solids level was 67". Removing 15.95" would leave 51.05". TC-3 on the R-14 tree is located at the 52 " liquid level and should, therefore, have been exposed to tank supernate.

This thermocouple did show an immediate temperature response to the tank liquid temperature, see Figure 1. It subsequently showed a temperature rise to a temperature approximately half way between its pre-batch temperature and the temperature of the tank liquid. This temperature then began showing a downward trend which would have reached the tank liquid temperature in roughly two months - approximately the same settling period noted in tank 241-AY-102 using the ENRAF densitometer. This response is interpreted as showing that the solids in the tank had been fluffed just as in tank 241-AY-102 covering TC-3 with very little settled material which prevented, or at least significantly reduced, convective cooling. The subsequent compaction of these fluffed solids in conjunction with the general cooling of the tank due to removal of nearly 16 inches of insulating sludge produced the observed downward temperature trend. The upward TC-3 temperature trend experienced beginning on March 18, 1999 was the result of the transfer line flush which added cool liquid to the tank. This reduced the evaporative cooling until the cool fluid could be heated to the original tank liquid temperature

2. The tank 24I-AY-102 MIT thermocouples - The fixed MIT thermocouples show data verv similar to the MIT validation probe, discussed below. They are, therefore, considered to support a mass transfer at least as high as that calculated above

3. The tank 241-AY-102 MIT validation probe temperature profile - Figure 2 compares the ENRAF densitometer solids levels to those inferred from the MIT validation probe measurements. Since the start of sluicing operations, the MIT data shows the interface of the conductive / non-conductive zones in tank 241-AY-102 to be approximately ten inches above the solids level measured by the densitometer. 
This difference in level may come from several sources or groups of sources as discussed below. However, the MIT data would definitely not support a transferred solids volume less than that calculated by the settled solids methodology.

Possible explanations for the different levels determined by the densitometer and MIT validation probe include:

a. The densitometer potential wire dragging causing lower readings.

b. The different physical properties being measured by the two instruments, ie., a pre-set change in measured density (densitometer) and the point at which enough solids have accumulated in the waste to cause it to no longer allow convective fluid flow.

c. A reference level error in the MIT instrument

The MIT data differences will be investigated further after the densitometer wire dragging problem is resolved, if the measurement differences at that time warrant further investigation.

B. Inconclusive Process Control Data - Process control data which is considered inconclusive or anomalous is the ENRAF densitometer density profiles.

The data from the ENRAF densitometer density profiles has been evaluated and is not providing meaningful data. This density profile data source is therefore considered inconclusive.

Most of the density profiles from the densitometer show the lowest measured density at a level well below the liquid surface (most frequently at 84 "). This is technically impossible - having a more dense fluid on top of a less dense fluid. This anomalous data is believed to be the result of the densitometer plummet support wire dragging on the inside surface of the four inch riser during part of the plummet travel. This is projected to occur because the four inch riser is not completely plumb.

In addition, during periods when no solids transfers are occurring, the density profiles show a change in the total quantity of solids present in the tank, ie., the data is inconsistent

The sediment level data from the densitometer is being used. The uncertainties associated with using the sediment levels are evaluated below.

\section{CALCULATION UNCERTAINTY ESTIMATES}

There are numerous sources of uncertainty inherent in calculating the volume of waste solids removed from tank 241-C-106. A comprehensive assessment of the uncertainty is not possible at this time. A 


\section{FIGURE 1}

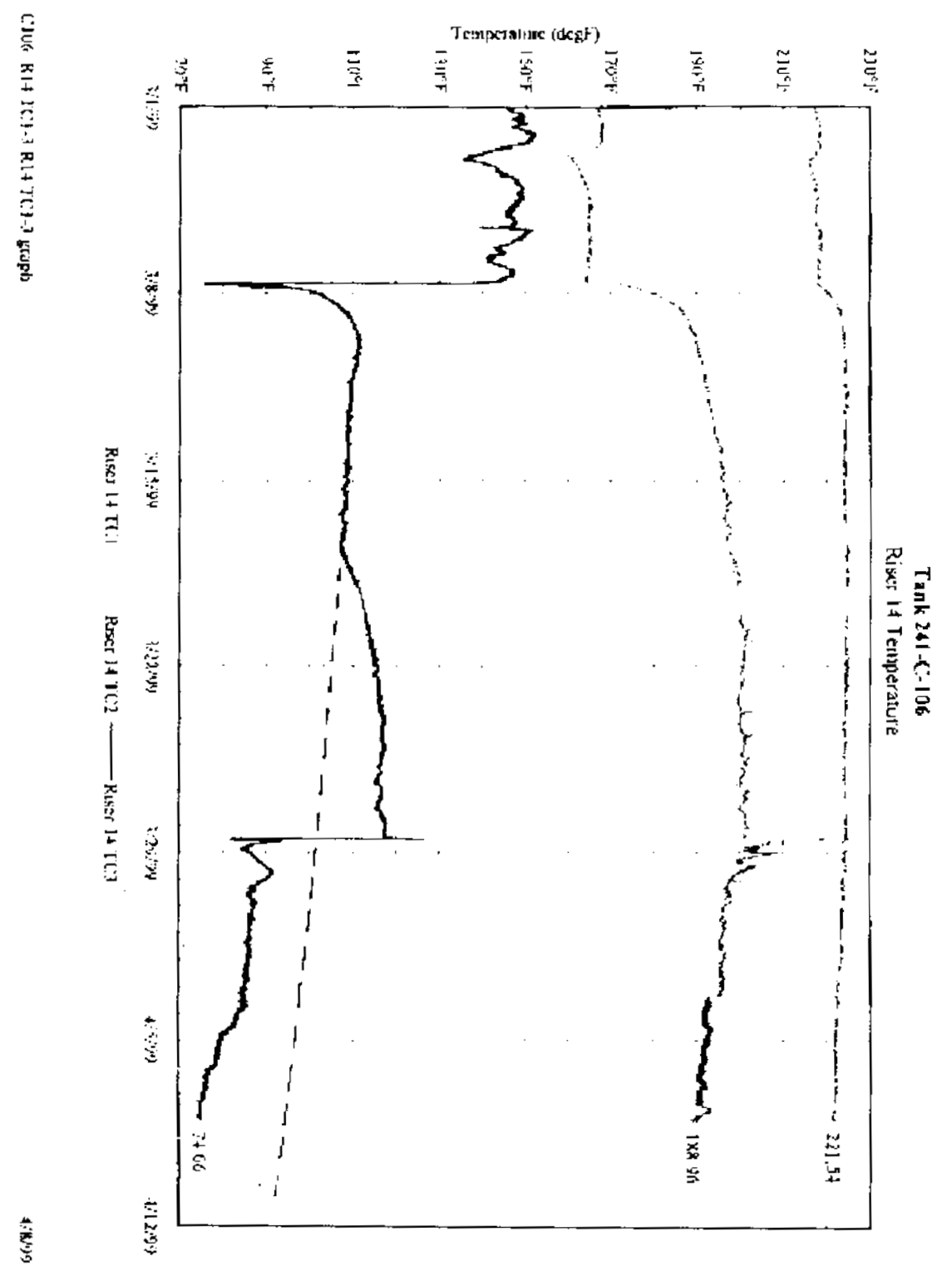


FIGURE 2

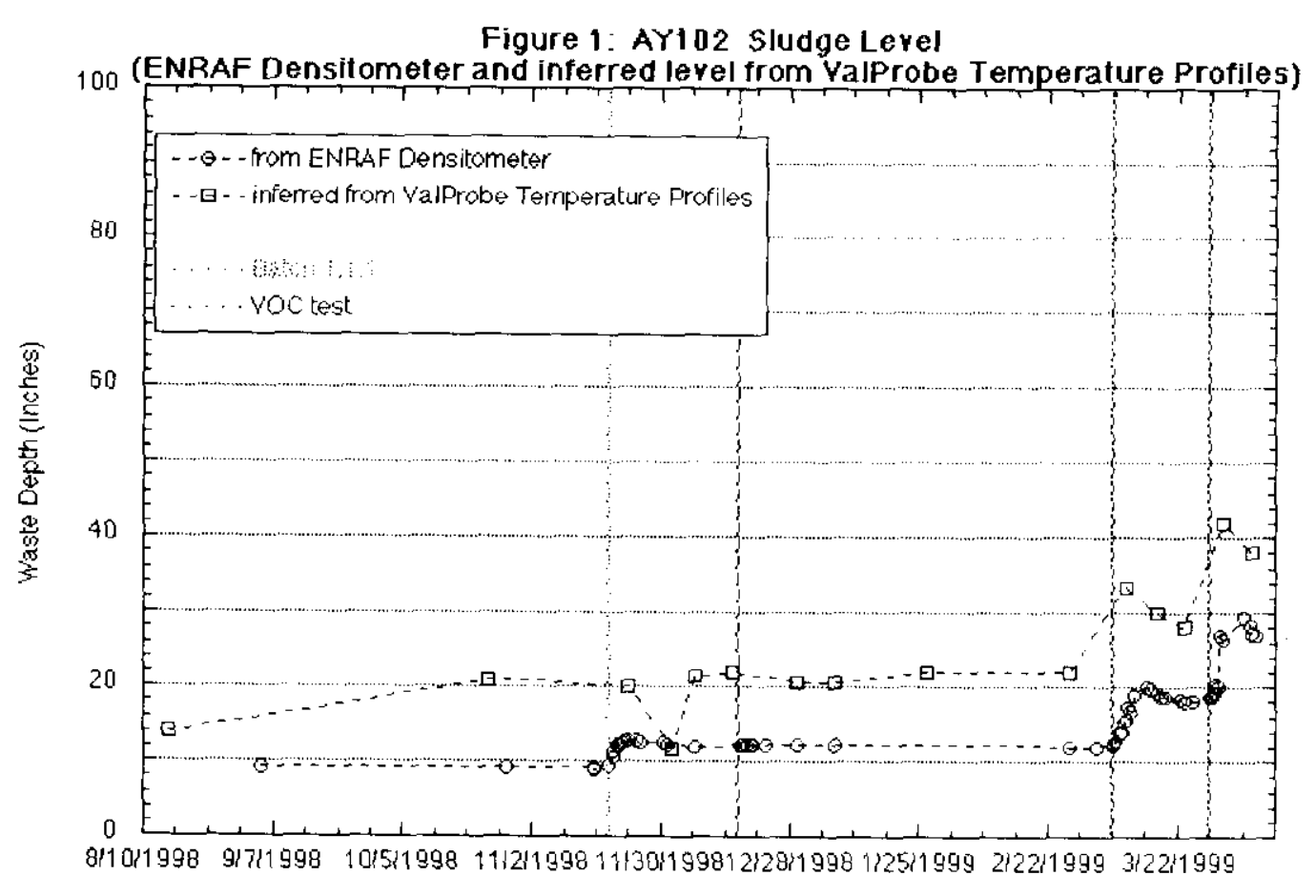

rough approximation of the impact of these uncertainties on the accuracy of the calculated solids volume is included in this section of the calculation.

Based on the calculations contained in the following section, the ranges of uncertainty in the three parts of the solids volume calculations are.

Mass Flow Meter -

$$
\pm 10.2 \text { inches }(28,050 \text { gal. })
$$

Verifying Process Control Information Uncertainties

Settled Solids Volume -

Dissolved Solids Volume -

Total -
$+0.16 "$ to $-0.99 "$

$(+440$ to $-2,720$ gal. $)$

+3.8 inches $(10,450$ gallons $)$

+4.0 to -4.8 inches

( $+11,000$ to $-13,200$ gallons $)$ 
Because the final volume transferred calculation should be no more uncertain than the least uncertain of the two input calculations, the final volume transferred calculation uncertainty is +4.0 to -4.8 inches $(+11,000$ to $-13,200$ gallons $)$

I. Mass Flow Meter Data Uncertainty - Instrument accuracy for the mass flow meter has been determined by testing of an identical mass flow meter in a test loop. The testing, conducted by PNNL, determined the uncertainty range to be \pm 40 to $50 \%$ when the slurry solids loading was below $10 \%$ and \pm 20 to $40 \%$ when the slurry solids loading was above $10 \%$, reference HNF-SD-W320-DB001, "Design Basis Document Project W-320 Tank 24I-C-106 Sluicing", Appendix. Data from the first sluicing campaign indicates that the mass flow meter solids volume values are more accurate than that determined by PNNL.

The slurry solids loading experience during the first campaign ranged between approximately $0 \%$ and $14 \%$. The $\pm 40 \%$ value from the PNNL testing was selected because the actual sluicing solids loading ranged around the $10 \%$ value which is the dividing point for the PNNL uncertainty range estimates. The $40 \%$ value was a limit for the each of the two ranges and was therefore selected. It should provide an appropriate approximation of the accuracy of the mass flow data for the WRSS sluicing operations conducted to date.

Applying the $40 \%$ uncertainty to the 25.4 inches $(69,850$ gal.) mass flow meter transferred volume gives an uncertainty of $\pm \mathbf{1 0 . 2}$ inches $(28,050$ gal.)

I1. Settled Solids Volume Calculation Uncertainty - The instrumentation supporting the settled solids volume is the ENRAF densitometer. The densitometer sediment level measurement accuracy is \pm 2 mm (0.08"). This uncertainty equates to 220 gallons in tank 241-AY-102. However, the main sources of positive uncertainty in the settled solids volume calculation is the assumptions made in projecting the solids settling behavior based on prior settling measurement data. The instrument error is neglected in the negative uncertain because it is insignificant compared to the assumption induced error. The positive uncertainty associated with the error from the postulated densitometer plummet support wire dragging, discussed below, is the same order of magnitude as the instrument error and these two sources are summed to give the positive uncertainty $(0.08 "+0.08 ")=0.16^{\prime \prime}$

Based on the calculations below, the settled solids volume uncertainty is $+\mathbf{0 . 1 6}$ " to $0.99 "$ (+ 440 to $-2,720$ gal. $)$

A. Settled Solids Volume Negative Uncertainty - The main potential cause of settled solids volume negative uncertainty is the assumption that the slow settling period is complete after three months. This assumption was used in developing the Batch 1.1 .1 and process test phase 1 baseline. If this assumption is in error, the subsequent settled solids volume calculations would be higher than the actual final settled solids volumes. The following calculations are used to assess the potential negative error in the settled solids volume.

To assess the maximum potential impact of this assumption being incorrect, the settling time to final compaction is doubled to six months. Doubling the settling period is considered to bound 
the potential range of the settling period because densitometer sediment level data from immediately before process test phase II no longer showed a downward trend. The values used in the following calculations come from Sections II A through II.D, above

Assuming the slow settling rate remained unchanged during the extended period (a conservative assumption), the 0.27 " $(0.97 "-0.70$ ") settling would increase to 0.54 ". Applying this compaction to the waste volume transferred by Batch 1.1.1 and process test phase I gives a transferred volume of $2.55^{\prime \prime}(2.82$ " -0.27 " additional settling). If this value is then used in developing the projections of the final settled solid volumes transferred in process test phases II and III, the calculated settled solids volume for these batches are

Process Test Phase II $-\quad\left(8.23 "-2.1 l^{\prime \prime}-(2.11 " \mathrm{X}(0.54 " / 0.70 "))=4.49 "\right.$

Process Test Phase IIl - $\quad(11.35 " X(4.49 " / 8.23 "))=6.19 "$

The total compacted, settled solids volume would be the sum of these three figures, $\left(2.55^{\prime \prime}+\right.$ $\left.4.49^{\prime \prime}+6.19^{\prime \prime}\right)=13.23^{\prime \prime}$.

Comparing this volume to the previously calculated value, 14.22" gives a negative uncertainty of $(14.22-13.23)=0.99 "$.

B. Settled Solids Volume Positive Uncertainty - The main potential cause of settled solids volume negative uncertainty is the postulated ENRAF densitometer error caused by dragging of the plummet support wire on either a slightly non-plumb installation riser or on an internal component of the densitometer assembly.

The wire dragging problem has been postulated to explain the observed densitometer profile measurements which generally show a minimum fluid density at an elevation at or near 85 inches with densities increasing in both directions from there. Increasing density in the upward direction is a physically impossible condition in a low viscosity liquid

To assess the potential impact of the wire dragging phenomenon on the settled solids volume calculation, one must understand how the densitometer sediment levels are determined. A solids free liquid density is input to the densitometer. The densitometer is then lowered until a small pre-set increase in density is detected. The level at which this density increase is detected is recorded as the tank solids level (identified as sediment level in the densitometer activity $\log$ ).

If a density higher than the solids free liquid density is input to the densitometer, the plummet will penetrate further into the lightly settled solids before detecting the pre-set density increase, thereby, recording a solids level lower than that actually present in the tank.

The solids free liquid density value was initially taken as the densitometer measured density at a point approximately two feet below the liquid surface. Because of the 
inverted density profile measured in the upper portion of the liquid, postulated to be caused by the dragging of the densitometer plummet wire, the two foot level density was not the lowest density measured in the liquid. Even the lowest density measured in the liquid may in fact not be the solids free liquid density, but rather a partially clarified liquid density.

To approximate the potential error caused by the using the densitometer measured density two feet below the liquid surface, the difference between this measurement and the lowest density measured and the standard deviation for the error value is calculate. Two standard deviations are then assumed to provide reasonable confidence that the error has been bounded. The effect of this bounding error value on the measured solids level is then calculated to establish the positive uncertainty in the solids level value

From the calculation in Appendix A, the standard deviation between the density measured at two feet and the minimum liquid density is $S=\mathbf{0 . 0 0 3 7 9}$. Two standard deviations would give a density (Specific Gravity [SpG]) error of 0.00758

Next we determine the densitometer solids level measurement error associated with this error in the solids free liquid SpG error. This is accomplished by comparing this $\mathrm{SpG}$ change to densitometer data from two sediment level determinations performed consecutively using two different solids free liquid SpG inputs. The densitometer sediment level runs that were performed between April 5, 1999 through April 7, 1999 produced the data below.

\begin{tabular}{|c|c|c|c|c|}
\hline Date & $\frac{\text { Sediment }}{\text { Level (In.) }}$ & SpG Used & $\frac{\text { Delta Level }}{\text { (Inches) }}$ & Delta SpG \\
\hline $4 / 5$ & 29.45 & 1.08484 & $5.02 "$ & 0.3957 \\
\hline $4 / 5$ & 24.38 & 1.48057 & & \\
\hline $4 / 6$ & 28.29 & 1.08588 & $3.59 \%$ & 0.3178 \\
\hline $4 / 6$ & 24.70 & 1.40372 & & \\
\hline $4 / 7$ & 27.36 & 1.08564 & $2.71^{\prime \prime}$ & 0.3229 \\
\hline $4 / 7$ & 24.65 & 1.40885 & & \\
\hline
\end{tabular}

Dividing the level changes by the SpG changes to produce the normalized correction factor gives: $12.69,11.30$, and 8.39 . Averaging these values to produce an average correction factor gives 10.79

Assuming the ratio of the difference in solids levels versus the differences in input SpGs would hold for the two standard deviations change in $\mathrm{SpG}$ gives a reduction in solids level of $\mathbf{0 . 0 8 2}$ inches (225 gallons).

III. Dissolved Solids Volume CalculationUncertainty - The dissolved solids volume uncertainty is a function of the accuracy of the density values used in its development. This uncertainty is estimated 
WRSS CAMPAIGN \#1 SOLIDS VOLUME

TRANSFERRED CALCULATION
HNF-4379, Revision 0

Page 18 of 34

by evaluating the density measurement deviations and the impact these would have on the dissolved solids calculation.

The density measurement uncertainty is assessed by comparing the ranges of values for solids free liquids densities from sets of grab samples. From this we can determine the deviations from the average value. The associated standard deviation is then calculated. To bound the potential error in the calculated dissolved solids volume an error band of two standard deviations is then assumed. This error band is next used to calculate the dissolved solids volume at the two extremes of the possible density values. The resulting maximum and minimum dissolved solids values are then used to determine the uncertainty range for the calculated dissolved solids volume.

The grab sample SpG analytical results from the phase $I 1$ and phase IIl process test are used to calculate the standard deviation for grab sample $S p G$ data. The subject $\mathrm{SpG}$ data is provided below:

\section{Process Test Phase II SpG Data}

$1.063,1.063,1.066,1.061$, $1.064,1.053,1.038,1.069$

$1.066,1.058,1.070,1.055$

Average $\mathrm{SpG}=1.061$

\section{Process Test Phase III SoG Data}

$1.095,1.092,1.088,1.090$

Average $S p G=1.095$

Calculating the standard deviation in the same way shown in Appendix A

$$
\begin{aligned}
\mathrm{S}= & {\left[\left((1.063-1.061)^{2}+(1.063-1.061)^{2}+(1.066-1.061)^{2}+(1.061-1.061)^{2}+(1.064\right.\right.} \\
& -1.061)^{2}+(1.053-10.61)^{2}+(1.038-1.061)^{2}+(1.069-1.061)^{2}+(1.066- \\
& 1.061)^{2}+(1.058-1.061)^{2}+(1.070-1.061)^{2}+(1.055-1.061)^{2}+(1.095-1.095)^{2} \\
& \left.\left.+(1.092-1.095)^{2}+(1.088-1.095)^{2}+(1.090-1.095)^{2}\right) /(16-1)\right]^{-2} \\
\mathrm{~S}= & {[(0.000004+0.000004+0.000025+0+0.000009+0.000064+0.000529+} \\
& 0.000064+0.000025+0.000009+0.000081+0.000036+0+0.000009+0.000049 \\
& +0.000025) / 15]^{2} \\
\mathrm{~S}= & (0.000933 / 15)^{2}=\mathbf{0 . 0 0 7 8 9}
\end{aligned}
$$

Two standard deviations (0.0158) are used to bound the maximum uncertainty. If this SpG error is then add and subtracted from the value for the change in $\mathrm{SpG}$ used to calculate the dissolved solids volume and the calculation carrier out with the modified SpG values, the resulting calculated dissolved solids volumes are 14.7" and 7.1", respectively. This equates to a dissolved solids volume uncertainty of \pm 3.8 " (10,450 gal.). 
WRSS CAMPAIGN \#1 SOLIDS VOLUME

TRANSFERRED CALCULATION
HNF-4379, Revision 0

Page 19 of 34

\section{CONCLUSIONS}

This calculation fully meets its intended objective and purpose. The uncertainties associated with the solids transfer values have been estimated.

\section{RECOMMENDATIONS}

1. An evaluation of the total volume of waste remaining in tank 241-C-106 should be accomplished during Campaign \#2. The evaluation would pump tank $241-\mathrm{C}-106$ to as close to zero liquid content as possible while monitoring the level rise in tank $241-\mathrm{AY}-102$.

This technique allows a more accurate calculation of the volume of solids remaining in tank $241-\mathrm{C}$ 106. The remaining uncertainty is the volume of liquid puddles remaining in tank $241-\mathrm{C}-106$ after pumping to minimum liquid level. The in-tank imaging system will have to be fully functional to support this evaluation.

2. Additional evaluation of the ENRAF densitometer is needed to correct the postulated wire dragging problem if possible to make the density profile data useful. Evaluations simulated correcting the wire dragging problem appeared to indicate that if the problem were corrected, the data would correlate fairly well with other process control information.

\section{REFERENCES}

1. Carothers, K. G., 1999, EXCEL spread sheet, "WRSS Sample Data", Richland, Washington

2. LMHC 1999a, "Tank Waste Remediation System Process Engineering Instruction Manual",HNF-SD-WM-PROC-021, Lockheed Martin Hanford Corporation for Fluor Daniel Hanford, Inc., Richland Washington

3. LMHC 1999b, "Tank 241-C-106 Waste Retrieval Sluicing System Process Control Plan", HNF-SD-WM-PCP-013, Revision 1B, Lockheed Martin Hanford Corporation for Fluor Daniel Hanford, Inc., Richland Washington

4. McGraw-Hill Book Company, 1973, Chemical Engineer's Handbook - Fitth Edition, N.Y., N.Y

5. NHC 1998, "Design Basis Document Project W-320 Tank 241-C-106 Sluicing", HNF-SDW320-DB-001, Revision 2, Numatec Hanford Company for Fluor Daniel Hanford, Inc., Richland Washington 


\section{APPENDIX A}

\section{SOLIDS FREE LIQUID DENSITY ERROR STANDARD DEVIATION CALCULATION}

Prepared By J. W. Bailey, April 13, 1999

The data from the densitometer profiles taken between November 18, 1998 and March 18,1999 are used to establish the standard deviation for the purposes of assessing the Campaign \#1 settled solids volume uncertainty. This profile time frame was selected because it includes virtually all the measurements used in calculating the settled solids volume. A few profiles taken after the process test phase IIl operations have been excluded due to changes in the location of the value used for the solids free liquid density. These changes make these latter profiles non-representative. The densitometer profile data used to develop the standard deviation follows at the end of this calculation.

The formula for the standard deviation follows:

$$
S^{2}=\sum_{i=1}^{n}\left(X_{1}-\bar{X}\right)^{2} /(n-1)
$$

where $X_{1}, X_{2}, \ldots, X_{n}$ are the observations, reference Chemical Engineer's Handbook Fifth Edition.

The two foot level versus minimum density differences $\left(D_{1}\right.$ through $\left.D_{n}\right)$ calculated in each of the 34 profiles at the end of this calculation are listed below

$0.01156,0.01098,0.01115,0.01133,0.01066,0.01022,0.01001,0.01004,0.01018$, $0.01123,0.01128,0.00571,0.01146,0.01055,0.00550,0.00618,0.00668,0.00000$, $0.00051,0.00867,0.00014,0.00341,0.00016,0.00012,0.00526,0.00473,0.00468$, $0.00539,0.00544,0.00680,0.00565,0.00556,0.00517,0.00555$

Averaging these values give a $D_{\text {avg }}$ of 0.00682

The calculation of the standard deviation follows:

$$
\begin{aligned}
& S=\left[\left((0.00682-0.01156)^{2}+(0.00682-0.01098)^{2}+(0.00682-0.01115)^{2}+(0.00682-\right.\right. \\
& 0.01133)^{2}+(0.00682-0.01066)^{2}+(0.00682-0.01022)^{2}+(0.00682-0.01001)^{2}+(0.00682- \\
& 0.01004)^{2}+(0.00682-0.01018)^{2}+(0.00682-0.01123)^{2}+(0.00682-0.01128)^{2}+(0.00682- \\
& 0.00571)^{2}+(0.00682-0.01146)^{2}+(0.00682-0.01055)^{2}+(0.00682-0.00550)^{2}+(0.00682- \\
& 0.00618)^{2}+(0.00682-0.00668)^{2}+(0.00682-0.00000)^{2}+(0.00682-0.00051)^{2}+(0.00682- \\
& 0.00867)^{2}+(0.00682-0.00014)^{2}+(0.00682-0.00341)^{2}+(0.00682-0.00016)^{2}+(0.00682- \\
& 0.00012)^{2}+(0.00682-0.00526)^{2}+(0.00682-0.00473)^{2}+(0.00682-0.00468)^{2}+(0.00682-
\end{aligned}
$$




\section{APPENDIX A}

$0.00539)^{2}+(0.00682-0.00544)^{2}+(0.00682-0.00680)^{2}+(0.00682-0.00565)^{2}+(0.00682-$ $\left.\left.0.00556)^{2}+(0.00682-0.00517)^{2}+(0.00682-0.00555)^{2}\right) /(34-1)\right]^{2}$

$S=[(0.0000225+0.0000173+0.0000187+0.0000203+0.0000147+0.0000116+0.0000102$ $+0.0000104+0.0000113+0.0000194+0.0000199+0.0000012+0.0000215+0.0000139+$ $0.0000017+0.0000004+0.00000002+0.0000465+0.0000398+0.0000034+0.0000446+$ $0.0000116+0.0000444+0.0000449+0.0000024+0.0000044+0.0000046+0.0000020+$ $0.0000019+0.0000000+0.0000014+0.0000016+0.0000027+0.0000016) / 33]^{-2}$

$S=(.0004728 / 33)^{-2}=\mathbf{0 . 0 0 3 7 9}$

TANK 241-AY-102 DENSITOMETER PROFILE ACTIVITY LOG DATA AND 2 FOOT VS. MIN. DENSITY DIFFERENCE

\begin{tabular}{|c|c|c|c|}
\hline \multicolumn{2}{|c|}{ Density Profile start: } & $11-18-1998$ & $22: 15: 59$ \\
\hline Date & Time & Level & $\operatorname{Spg}$ \\
\hline \multicolumn{4}{|c|}{ 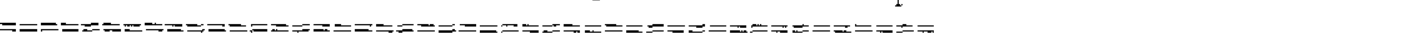 } \\
\hline $11-18-1998$ & $21: 38: 23$ & 155.95 & 1.05129 \\
\hline $11-18-1998$ & $21: 41: 24$ & 143.95 & 1.05137 \\
\hline $11-18-1998$ & $21: 44: 25$ & 131.95 & 1.05048 = $2 \mathrm{FT}$ LEVEL \\
\hline $11-18-1998$ & $21: 47: 26$ & 119.95 & 1.04683 \\
\hline $11-18-1998$ & $21: 50: 27$ & 107.95 & 1.04607 \\
\hline $11-18-1998$ & $21: 55: 19$ & 95.98 & 1.04431 \\
\hline $11-18-1998$ & $21: 58: 20$ & 83.95 & $1.03892=$ MINUMUM LENSITY \\
\hline $11-18-1998$ & $22: 01: 21$ & 71.95 & 1.04048 \\
\hline $11-18-1998$ & $22: 04: 22$ & 59.95 & 1.04247 \\
\hline $11-18-1998$ & $22: 07: 23$ & 47.95 & 1.04331 \\
\hline $11-18-1998$ & $22: 10: 24$ & 35.95 & 1.0443 \\
\hline $11-18-1998$ & $22: 13: 25$ & 23.95 & 1.04695 \\
\hline
\end{tabular}

2 ET LEVEI DENSITY - MINIMUM $=0.01156$

$\begin{array}{llll}\begin{array}{l}\text { Density Profile Start: } \\ \text { Date }\end{array} & \begin{array}{l}11-19-1998 \\ \text { Level }\end{array} & \begin{array}{l}11: 44: 08 \\ \text { SpG }\end{array} \\ =================================== \\ 11-19-1998 & 11: 09: 41 & 155.95 & 1.07014 \\ 11-19-1998 & 11: 12: 42 & 143.95 & 1.06992 \\ 11-19-1998 & 11: 15: 43 & 131.95 & 1.06869=2 \text { FT LEVEL } \\ 11-19-1998 & 11: 18: 44 & 119.95 & 1.06582 \\ 11-19-1998 & 11: 21: 45 & 107.95 & 1.06449 \\ 11-19-1998 & 11: 25: 24 & 95.97 & 1.06225 \\ 11-19-1998 & 11: 28: 25 & 83.95 & 1.05771=\text { MINUMUM DENSITY } \\ 11-19-1998 & 11: 31: 26 & 71.95 & 1.05933 \\ 11-19-1998 & 11: 34: 27 & 59.95 & 1.06144 \\ 11-19-1998 & 11: 37: 28 & 47.95 & 1.06208\end{array}$




\section{APPENDIX A}

\begin{tabular}{llll}
$11-19-1998$ & $11: 43: 30$ & 23.95 & 1.06484 \\
2 FT LEVEL DENSITY - MINIMUM $=0.01098$ & \\
\multicolumn{5}{c}{} \\
Density Profile Start: & $11-19-1998$ & $13: 28: 56$ \\
Date & Time & Level & SpG \\
$=================================$ \\
$11-19-1998$ & $12: 55: 06$ & 155.95 & 1.07045 \\
$11-19-1998$ & $12: 58: 07$ & 143.95 & 1.06975 \\
$11-19-1998$ & $13: 01: 08$ & 131.95 & $1.06782=2$ FT LEVEL \\
$11-19-1998$ & $13: 04: 09$ & 119.95 & 1.06513 \\
$11-19-1998$ & $13: 07: 10$ & 107.95 & 1.06396 \\
$11-19-1998$ & $13: 10: 29$ & 95.96 & 1.06176 \\
$11-19-1998$ & $13: 13: 30$ & 83.95 & $1.05667=$ MINUMUM DENSITY \\
$11-19-1998$ & $13: 16: 31$ & 71.95 & 1.05866 \\
$11-19-1998$ & $13: 19: 32$ & 59.95 & 1.06079 \\
$11-19-1998$ & $13: 22: 33$ & 47.95 & 1.06123 \\
$11-19-1998$ & $13: 25: 34$ & 35.95 & 1.06171 \\
$11-19-1998$ & $13: 28: 35$ & 23.95 & 1.06427
\end{tabular}

2 FT LEVEL DENSITY - MINIMUM $=0.01115$

\begin{tabular}{|c|c|c|c|}
\hline Density $\mathrm{Pr}$ & le Start: & $11-19-1998$ & $20: 13: 02$ \\
\hline Date & Time & Level & $\operatorname{SpG}$ \\
\hline$==== \pm==== \pm=$ & $== \pm== \pm=:==$ & 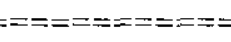 & $===$ \\
\hline $11-19-1998$ & $19: 39: 18$ & 155.95 & 1.06769 \\
\hline $11-19-1998$ & $19: 42: 19$ & 143.95 & 1.06599 \\
\hline $11-19-1998$ & $19: 45: 20$ & 131.95 & $1.06449=2 \mathrm{ET} \mathrm{LEVEL}$ \\
\hline $11-19-1998$ & $19: 48: 21$ & 119.95 & 1.06202 \\
\hline $11-19-1998$ & $19: 51: 22$ & 107.95 & 1.05999 \\
\hline $11-19-1998$ & $19: 54: 33$ & 95.95 & 1.05922 \\
\hline $11-19-1998$ & $19: 57: 34$ & 83.95 & $1.05316=$ MINUMUM DENSITY \\
\hline $11-19-1998$ & $20: 00: 35$ & 71.95 & 1.0549 \\
\hline $11-19-1998$ & $20: 03: 36$ & 59.95 & 1.05707 \\
\hline $11-19-1998$ & $20: 06: 37$ & 47.95 & 1.05853 \\
\hline $11-19-1998$ & $20: 09: 38$ & 35.95 & 1.05862 \\
\hline $11-19-1998$ & $20: 12: 39$ & 23.95 & 1.06053 \\
\hline
\end{tabular}

2 FT LEVEL DENSITY - MINIMUM $=0.01133$

\begin{tabular}{|c|c|c|c|}
\hline Density Pro & le Start: & $11 \cdot 19-1998$ & $20: 54: 45$ \\
\hline Date & Time & Level & $\operatorname{spg}$ \\
\hline$====-=====0$ & $==\approx==:===-$ & $== \pm===\therefore====$ & $===$ \\
\hline $11-19-1998$ & $20: 20: 58$ & 155.95 & 1.06615 \\
\hline $11-19-1998$ & $20: 23: 59$ & 143.95 & 1.06534 \\
\hline $11-19-1998$ & $20: 27: 00$ & 131.95 & $1.06355=2 \mathrm{FT}$ LEVEL \\
\hline $11-19-1998$ & $20: 30: 01$ & 119.95 & 1.06102 \\
\hline $11-19-1998$ & $20: 33: 02$ & 107.95 & 1.06021 \\
\hline $11-19-1998$ & $20: 36: 09$ & 95.95 & 1.05925 \\
\hline
\end{tabular}




\section{APPENDIX A}

$\begin{array}{llll}11-19-1998 & 20: 39: 10 & 83.95 & 1.05289=\text { MINUMUM DENSITY } \\ 11-19-1998 & 20: 42: 11 & 71.95 & 1.05423 \\ 11-19-1998 & 20: 45: 12 & 59.95 & 1.05713 \\ 11-19-1998 & 20: 48: 13 & 47.95 & 1.05789 \\ 11-19-1998 & 20: 51: 14 & 35.95 & 1.05793 \\ 11-19-1998 & 20: 54: 15 & 23.95 & 1.00014\end{array}$

2 FT LEVEL DENSITY - MINIMUM $=0.01066$

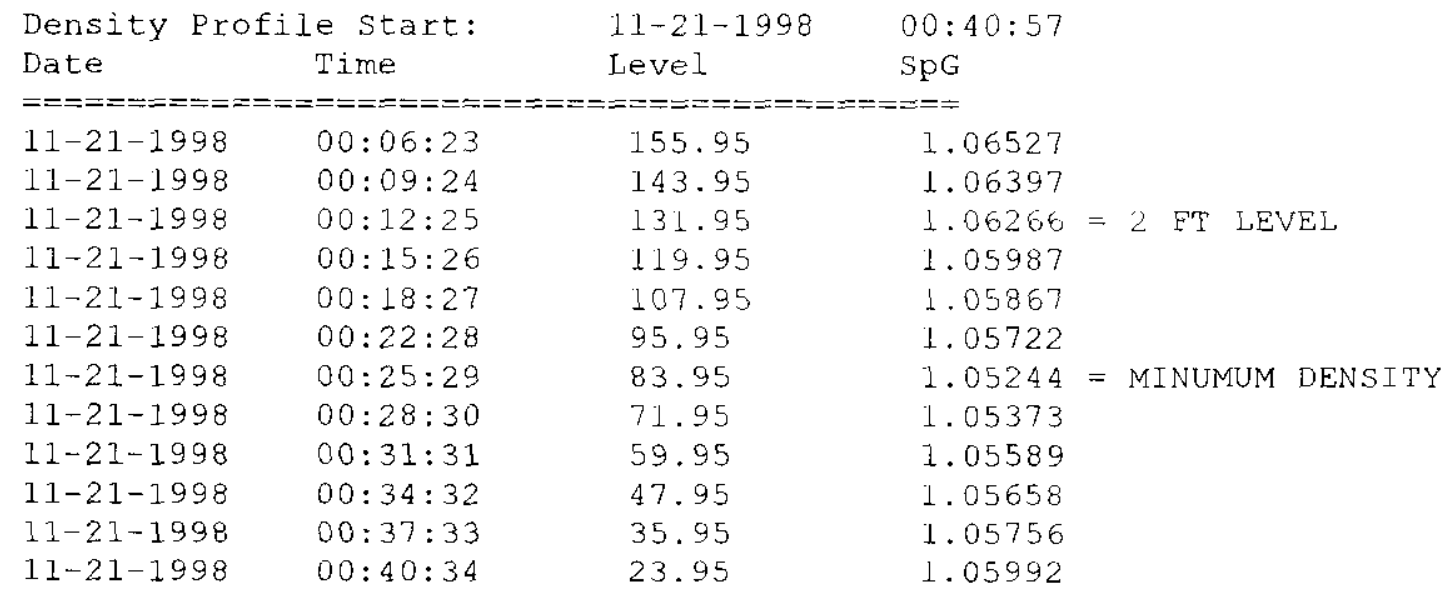

2 FT LEVEL DENSITY - MINIMUM $=0.01022$

$\begin{array}{llll}\begin{array}{l}\text { Density Profile Start: } \\ \text { Date }\end{array} & \begin{array}{l}11-21-1998 \\ \text { Time }\end{array} & \begin{array}{l}01: 2.8: 53 \\ \text { Level }\end{array} & \begin{array}{l}\text { SpG } \\ ==================================\end{array} \\ 11-21-1998 & 00: 55: 07 & 155.95 & 1.0647 \\ 11-21-1998 & 00: 58: 08 & 143.95 & 1.06397 \\ 11-21-1998 & 01: 01: 09 & 131.95 & 1.06237=2 \text { FT LEVEL } \\ 11-21-1998 & 01: 04: 10 & 119.95 & 1.05966 \\ 11-21-1998 & 01: 07: 11 & 107.95 & 1.05838 \\ 11-21-1998 & 01: 10: 17 & 95.95 & 1.05665 \\ 11-21-1998 & 01: 13: 18 & 83.95 & 1.05236=\text { MINUMUM DENSITY } \\ 11-21-1998 & 01: 16: 19 & 71.95 & 1.05354 \\ 11-21-1998 & 01: 19: 20 & 59.95 & 1.05637 \\ 11-21-1998 & 01: 22: 21 & 47.95 & 1.05664 \\ 11-21-1998 & 01: 25: 22 & 35.95 & 1.05744 \\ 11-21-1998 & 01: 28: 23 & 23.95 & 1.05982\end{array}$

2 FT LEVEL DENSITY - MINIMUM $=0.01001$

$\begin{array}{llll}\text { Density } & \text { Profile Start: } & 12-01-1998 & 10: 32: 49 \\ \text { Date } & \text { Time } & \text { Level } & \text { SpG }\end{array}$ 


\section{APPENDIX A}

$\begin{array}{llll}12-01-1998 & 09: 59: 26 & 155.95 & 1.05956 \\ 12-01-1998 & 10: 02: 27 & 143.95 & 1.05916 \\ 12-01-1998 & 10: 05: 28 & 131.95 & 1.05768=2 \text { FT LEVEL } \\ 12-01-1998 & 10: 08: 29 & 119.95 & 1.05506 \\ 12-01-1998 & 10: 11: 30 & 107.95 & 1.05378 \\ 12-01-1998 & 10: 14: 34 & 95.95 & 1.05249 \\ 12-01-1998 & 10: 17: 35 & 83.95 & 1.04764=\text { MINUMUM DENSITY } \\ 12-01-1998 & 10: 20: 36 & 71.95 & 1.04872 \\ 12-01-1998 & 10: 23: 37 & 59.95 & 1.05016 \\ 12-01-1998 & 10: 26: 38 & 47.95 & 1.05197 \\ 12-01-1998 & 10: 29: 39 & 35.95 & 1.05173 \\ 12-01-1998 & 10: 32: 40 & 23.95 & 1.05444\end{array}$

2 FT LEVEL DENSITY - MINIMUM $=0.01004$

$\begin{array}{llll}\begin{array}{l}\text { Density Profile Start: } \\ \text { Date }\end{array} & \begin{array}{l}\text { Time } \\ \text { Level }\end{array} & \begin{array}{l}12: 07-1998 \\ \text { LpG }\end{array}================================ \\ 12-07-1998 & 13: 46: 15 & 155.95 & 1.05675 \\ 12-07-1998 & 13: 49: 16 & 143.95 & 1.05725 \\ 12-07-1998 & 13: 52: 17 & 131.95 & 1.05617=2 \text { FT LEVEL } \\ 12-07-1998 & 13: 55: 18 & 119.95 & 1.05297 \\ 12-07-1998 & 13: 58: 19 & 107.95 & 1.05189 \\ 12-07-1998 & 14: 01: 23 & 95.95 & 1.05 \\ 12-07-1998 & 14: 04: 24 & 83.95 & 1.04599=\text { MINUMUM DENSITY } \\ 12-07-1998 & 14: 07: 25 & 71.95 & 1.04668 \\ 12-07-1998 & 14: 10: 26 & 59.95 & 1.04791 \\ 12-07-1998 & 14: 13: 27 & 47.95 & 1.0489 \\ 12-07-1998 & 14: 16: 28 & 35.95 & 1.04914 \\ 12-07-1998 & 14: 19: 29 & 23.95 & 1.05186\end{array}$

2 FT LEVEI DENSITY - MINIMUM $=0.01018$

\begin{tabular}{|c|c|c|c|}
\hline Density Pro & e start: & $12-17-1998$ & $12: 12: 05$ \\
\hline Date & Time & Level & $\operatorname{spg}$ \\
\hline$=== \pm== \pm== \pm=$ & $========$ & $== \pm=== \pm===$ & $===$ \\
\hline $12-17-1998$ & $11: 38: 20$ & 155.95 & 1.07896 \\
\hline $12-17-1998$ & $11: 41: 21$ & 143.95 & 1.07897 \\
\hline $12-17-1998$ & $11: 44: 22$ & 131.95 & $1.07851=2 \mathrm{FT}$ LEVEL \\
\hline $12-17-1998$ & $11: 47: 23$ & 119.95 & 1.0757 \\
\hline $12-17-1998$ & $11: 50: 24$ & 107.95 & 1.07518 \\
\hline $12-17-1998$ & $11: 53: 28$ & 95.95 & 1.07263 \\
\hline $12-17-1998$ & $11: 56: 29$ & 83.95 & $1.06728=$ MINUMUM DENSITY \\
\hline $12-17-1998$ & $11: 59: 30$ & 71.95 & 1.06843 \\
\hline $12-17-1998$ & $12: 02: 31$ & 59.95 & 1.06959 \\
\hline $12-17-1998$ & $12: 05: 32$ & 47.95 & 1.07067 \\
\hline $12-17-1998$ & $12: 08: 33$ & 35.95 & 1.0713 \\
\hline $12-17-1998$ & $12: 11: 34$ & 23.95 & 1.07415 \\
\hline
\end{tabular}




\section{APPENDIX A}

2 FT LEVEL DENSITY - MINIMUM $=0.01123$

$\begin{array}{llll}\begin{array}{l}\text { Density Profile Start: } \\ \text { Date }\end{array} & \begin{array}{l}12-17-1998 \\ \text { Time }\end{array} & \begin{array}{l}12: 52: 55 \\ \text { Level }\end{array} & \begin{array}{l}\text { SpG } \\ ================================\end{array} \\ 12-17-1998 & 12: 18: 57 & 155.95 & 1.079 \\ 12-17-1998 & 12: 21: 58 & 143.95 & 1.0796 \\ 12-17-1998 & 12: 24: 59 & 131.95 & 1.07841=2 \text { FT LEVEL } \\ 12-17-1998 & 12: 28: 00 & 119.95 & 1.0754 \\ 12-17-1998 & 12: 31: 01 & 107.95 & 1.07481 \\ 12-17-1998 & 12: 34: 05 & 95.95 & 1.07156 \\ 12-17-1998 & 12: 37: 06 & 83.95 & 1.06713=\text { MINUMUM DENSITY } \\ 12-17-1998 & 12: 40: 07 & 71.95 & 1.06816 \\ 12-17-1998 & 12: 43: 08 & 59.95 & 1.06955 \\ 12-17-1998 & 12: 46: 09 & 47.95 & 1.07018 \\ 12-17-1998 & 12: 49: 10 & 35.95 & 1.07109 \\ 12-17-1998 & 12: 52: 11 & 23.95 & 1.07376\end{array}$

2 FT LEVEL DENSITY - MINIMUM $=0.01128$

\begin{tabular}{|c|c|c|c|}
\hline Density Pro & Le start: & $12-17-1998$ & $19: 50: 08$ \\
\hline Date & Time & Level & $\operatorname{SpG}$ \\
\hline$====:=====0$ & $==\approx=====-=$ & $======== \pm$ & $===$ \\
\hline $12-17-1998$ & $19: 15: 58$ & 155.95 & 1.05936 \\
\hline $12-17-1998$ & $19: 18: 59$ & 143.95 & 1.05917 \\
\hline $12-17-1998$ & $19: 22: 00$ & 131.95 & $1.05833=2 \mathrm{FT}$ LEVEL \\
\hline $12-17-1998$ & $19: 25: 01$ & 119.95 & 1.05646 \\
\hline $12-17-1998$ & $19: 28: 02$ & 107.95 & 1.05505 \\
\hline $12-17-1998$ & $19: 31: 06$ & 95.95 & $1.05262=$ MINUMUM DENSITY \\
\hline $12-17-1998$ & $19: 34: 07$ & 83.95 & 1.05812 \\
\hline $12-17-1998$ & $19: 37: 08$ & 71.95 & 1.05825 \\
\hline $12-17-1998$ & $19: 40: 09$ & 59.95 & 1.0609 \\
\hline $12-17-1998$ & $19: 43: 10$ & 47.95 & 1.06198 \\
\hline $12-17-1998$ & $19: 46: 11$ & 35.95 & 1.06339 \\
\hline $12-17-1998$ & $19: 49: 12$ & 23.95 & 1.06453 \\
\hline
\end{tabular}

\section{FT LEVEL DENSITY - MINIMUM $=0.00571$}

$\begin{array}{llll}\begin{array}{l}\text { Density Profile Start: } \\ \text { Date }\end{array} & \begin{array}{l}12-18-1998 \\ \text { Time }\end{array} & \begin{array}{l}14: 39: 54 \\ \text { Level }\end{array} & \text { SpG } \\ ================================== \\ 12-18-1998 & 14: 06: 04 & 155.95 & 1.07283 \\ 12-18-1998 & 14: 09: 05 & 143.95 & 1.07276 \\ 12-18-1998 & 14: 12: 06 & 131.95 & 1.07224=2 \text { FT LEVEL } \\ 12-18-1998 & 14: 15: 07 & 119.95 & 1.06963 \\ 12-18-1998 & 14: 18: 08 & 107.95 & 1.06804 \\ 12-18-1998 & 14: 21: 12 & 95.95 & 1.06577\end{array}$




\section{APPENDIX A}

$\begin{array}{llll}12-18-1998 & 14: 24: 13 & 83.95 & 1.06078=\text { MINUMUM DENSITY } \\ 12-18-1998 & 14: 27: 14 & 71.95 & 1.06194 \\ 12-18-1998 & 14: 30: 15 & 59.95 & 1.06327 \\ 12-18-1998 & 14: 33: 16 & 47.95 & 1.06403 \\ 12-18-1998 & 14: 36: 17 & 35.95 & 1.06498 \\ 12-18-1998 & 14: 39: 18 & 23.95 & 1.06773\end{array}$

2 FT LEVEL DENSITY - MINIMUM $=0.01146$

\begin{tabular}{|c|c|c|c|}
\hline Density Pro & le Start: & $12-18-1998$ & $15: 19: 41$ \\
\hline Date & Time & Level & $\operatorname{SpG}$ \\
\hline$==========$ & $===-===\leq==$ & $==:==-=\equiv=== \pm$ & $z===$ \\
\hline $12-18-1998$ & $14: 45: 33$ & 155.95 & 1.07233 \\
\hline $12-18-1998$ & $14: 48: 34$ & 143.95 & 1.07198 \\
\hline $12-18-1998$ & $14: 51: 35$ & 131.95 & $1.07098=2 \mathrm{FT}$ LEVEL \\
\hline $12-18-1998$ & $14: 54: 36$ & 119.95 & 1.06873 \\
\hline $12-18-1998$ & $14: 57: 37$ & 107.95 & 1.06737 \\
\hline $12-18-1998$ & $15: 00: 41$ & 95.95 & 1.06533 \\
\hline $12-18-1998$ & $15: 03: 42$ & 83.95 & $1.06043=$ MINUMUM DENSITY \\
\hline $12-18-1998$ & $15: 06: 43$ & 71.95 & 1.0618 \\
\hline $12-18-1998$ & $15: 09: 44$ & 59.95 & 1.0631 \\
\hline $12-18-1998$ & $15: 12: 45$ & 47.95 & 1.06409 \\
\hline $12-18-1998$ & $15: 15: 46$ & 35.95 & 1.06481 \\
\hline $12-18-1998$ & $15: 18: 47$ & 23.95 & 1.06766 \\
\hline
\end{tabular}

2 FT LEVEL DENSITY - MINIMUM $=0.01055$

\begin{tabular}{|c|c|c|c|}
\hline Density Pro & le start: & $12-18-1998$ & $19: 42: 11$ \\
\hline Date & Time & Level & $\operatorname{SpG}$ \\
\hline$== \pm==\approx== \pm= \pm$ & $========$ & $==========$ & $===$ \\
\hline $12-18-1998$ & $19: 08: 29$ & 155.95 & 1.05235 \\
\hline $12-18-1998$ & $19: 11: 30$ & 143.95 & 1.05268 \\
\hline $12-18-1998$ & $19: 14: 31$ & 131.95 & $1.05194=2 \mathrm{FT}$ LEVEL \\
\hline $12-18-1998$ & $19: 17: 32$ & 119.95 & 1.04972 \\
\hline $12-18-1998$ & $19: 20: 33$ & 107.95 & 1.0477 \\
\hline $12-18-1998$ & $19: 23: 37$ & 95.95 & $1.04644=$ MINUMUM DENSITY \\
\hline $12-18-1998$ & $19: 26: 38$ & 83.95 & 1.05153 \\
\hline $12-18-1998$ & $19: 29: 39$ & 71.95 & 1.05202 \\
\hline $12-18-1998$ & $19: 32: 40$ & 59.95 & 1.05428 \\
\hline $12-18-1998$ & $19: 35: 41$ & 47.95 & 1.05583 \\
\hline $12-18-1998$ & $19: 38: 42$ & 35.95 & 1.05651 \\
\hline $12-18-1998$ & $19: 41: 43$ & 23.95 & 1.05828 \\
\hline
\end{tabular}

2 FT LEVEL DENSITY - MINIMUM $=0.00550$

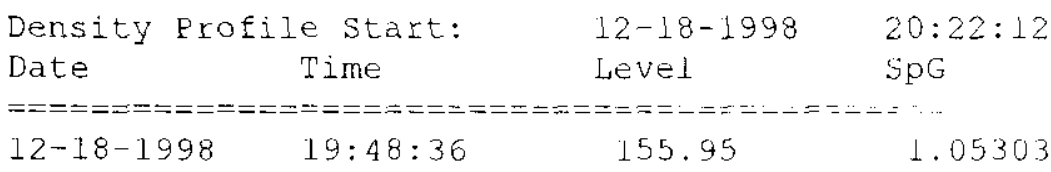




\section{APPENDIX A}

$\begin{array}{llll}12-18-1998 & 19: 51: 37 & 143.95 & 1.05282 \\ 12-18-1998 & 19: 54: 38 & 131.95 & 1.05122=2 \text { FT LEVEL } \\ 12-18-1998 & 19: 57: 39 & 119.95 & 1.04902 \\ 12-18-1998 & 20: 00: 40 & 107.95 & 1.04719 \\ 12-18-1998 & 20: 03: 44 & 95.95 & 1.04504=\text { MINUMUM DENSITY } \\ 12-18-1998 & 20: 06: 45 & 83.95 & 1.05113 \\ 12-18-1998 & 20: 09: 46 & 71.95 & 1.05152 \\ 12-18-1998 & 20: 12: 47 & 59.95 & 1.05458 \\ 12-18-1998 & 20: 15: 48 & 47.95 & 1.05491 \\ 12-18-1998 & 20: 18: 49 & 35.95 & 1.05696 \\ 12-18-1998 & 20: 21: 50 & 23.95 & 1.05792\end{array}$

2 FT LEVEL DENSITY - MINIMUM $=0.00618$

$\begin{array}{llll}\begin{array}{l}\text { Density Profile Start: } \\ \text { Date }\end{array} & \begin{array}{l}12-19-1998 \\ \text { Time }\end{array} & \begin{array}{l}14: 50: 42 \\ \text { LeVel }\end{array} & \begin{array}{l}\text { SpG } \\ ==================================\end{array} \\ 12-19-1998 & 14: 16: 24 & 155.95 & 1.06441 \\ 12-19-1998 & 14: 19: 25 & 143.95 & 1.06456 \\ 12-19-1998 & 14: 22: 26 & 131.95 & 1.06225=2 \text { FT LEVEL } \\ 12-19-1998 & 14: 25: 27 & 119.95 & 1.05902 \\ 12-19-1998 & 14: 28: 28 & 107.95 & 1.05791 \\ 12-19-1998 & 14: 31: 32 & 95.95 & 1.05557=\text { MINUMUM DENSITY } \\ 12-19-1998 & 14: 34: 33 & 83.95 & 1.06062 \\ 12-19-1998 & 14: 37: 34 & 71.95 & 1.06099 \\ 12-19-1998 & 14: 40: 35 & 59.95 & 1.06404 \\ 12-19-1998 & 14: 43: 36 & 47.95 & 1.0659 \\ 12-19-1998 & 14: 46: 37 & 35.95 & 1.06672\end{array}$

2 FT LEVEL DENSITY - MINIMUM $=0.00668$

$\begin{array}{llll}\begin{array}{l}\text { Density } \\ \text { Date }\end{array} & \begin{array}{l}\text { Time } \\ \text { Tate Start: }\end{array} & \begin{array}{l}12-19-1998 \\ \text { Level }\end{array} & \begin{array}{l}21: 12: 44 \\ \text { SpG }\end{array} \\ 12-19-1998 & 20: 38: 56 & 160.16 & 1.0607 \\ 12-19-1998 & 20: 41: 57 & 147.95 & 1.06269 \\ 12-19-1998 & 20: 44: 58 & 135.95 & 1.06001-\text { MINUMUM DENSITY } \\ & & & \\ 12-19-1998 & 20: 47: 59 & 123.95 & 1.06148 \\ 12-19-1998 & 20: 51: 00 & 111.95 & 1.06214 \\ 12-19-1998 & 20: 54: 01 & 99.95 & 1.0654 \\ 12-19-1998 & 20: 57: 02 & 87.95 & 1.06751 \\ 12-19-1998 & 21: 00: 03 & 75.95 & 1.06891 \\ 12-19-1998 & 21: 03: 04 & 63.95 & 1.06896 \\ 12-19-1998 & 21: 06: 05 & 51.95 & 1.06767 \\ 12-19-1998 & 21: 09: 06 & 39.95 & 1.06617\end{array}$

2 FT LEVEL DENSITY - MINIMUM $=0.00000$ 


\section{APPENDIX A}

\begin{tabular}{|c|c|c|c|}
\hline Density ero & le start: & $12-19-1998$ & $22: 56: 03$ \\
\hline Date & Time & Level & $\operatorname{SpG}$ \\
\hline 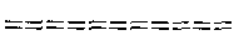 & $==ニ=ニ===$ & $== \pm==== \pm===$ & $===$ \\
\hline $12-19-1998$ & $22: 22: 24$ & 159.95 & $1.05995=$ MINUMUM DENSITY \\
\hline $12-19-1998$ & $22: 25: 25$ & 147.95 & 1.06209 \\
\hline $12-19-1998$ & $22: 28: 26$ & 135.95 & $1.06046=2 \mathrm{FT}$ LEVEL \\
\hline $12-19-1998$ & $22: 31: 27$ & 123.95 & 1.06138 \\
\hline $12-19-1998$ & $22: 34: 28$ & 111.95 & 1.0615 \\
\hline $12-19-1998$ & $22: 37: 29$ & 99.95 & 1.06526 \\
\hline $12-19-1998$ & $22: 40: 30$ & 87.95 & 1.06802 \\
\hline $12-19-1998$ & $22: 43: 31$ & 75.95 & 1.06842 \\
\hline $12-19-1998$ & $22: 46: 32$ & 63.95 & 1.0687 \\
\hline $12-19-1998$ & $22: 49: 33$ & 51.95 & 1.06758 \\
\hline $12-19-1998$ & $22: 52: 34$ & 39.95 & 1.06602 \\
\hline $12-19-1998$ & $22: 55: 38$ & 27.95 & 1.06251 \\
\hline
\end{tabular}

2 FT LEVEL DENSITY - MINIMUM $=0.00051$

\begin{tabular}{|c|c|c|c|}
\hline Density Pro & le start: & $03-04-1999$ & $13: 19: 07$ \\
\hline Date & Time & Level & $\operatorname{SpG}$ \\
\hline$=====:=== \pm=$ & $=========$ & $===\Rightarrow==-====$ & $=-2==$ \\
\hline $03-04-1999$ & $12: 45: 01$ & 155.95 & 1.0723 \\
\hline $03-04-1999$ & $12: 48: 02$ & 143.95 & 1.07215 \\
\hline $03-04-1999$ & $12: 51: 03$ & 131.95 & $1.07116=2$ ET LEVEI \\
\hline $03-04-1999$ & $12: 54: 04$ & 119.95 & 1.06879 \\
\hline $03-04-1999$ & $12: 57: 05$ & 107.95 & 1.0688 \\
\hline $03-04-1999$ & $13: 00: 09$ & 95.95 & 1.06768 \\
\hline $03-04-1999$ & $13: 03: 10$ & 83.95 & $1.06249=$ MINUMUM DENSITY \\
\hline $03-04-1999$ & $13: 06: 11$ & 71.95 & 1.06363 \\
\hline $03-04-1999$ & $13: 09: 12$ & 59.95 & 1.06465 \\
\hline $03-04-1999$ & $13: 12: 13$ & 47.95 & 1.06459 \\
\hline $03-04-1999$ & $13: 15: 14$ & 3.5 .95 & 1.06557 \\
\hline
\end{tabular}

2 FT LEVEL DENSITY - MINIMUM $=0.00867$

\begin{tabular}{|c|c|c|c|}
\hline Density Pro & Le start: & $03-08+1999$ & $02: 19: 52$ \\
\hline Date & Time & Level & SpG \\
\hline$======:===$ & $=========$ & $\therefore=\approx=\approx======$ & $==-=$ \\
\hline $03-08-1999$ & $01: 46: 23$ & 155.95 & 1.08458 \\
\hline $03-08-1999$ & $01: 49: 24$ & 143.95 & 1.08343 \\
\hline $03-08-1999$ & $01: 52: 25$ & 131.95 & $1.08255=2 \mathrm{ET} \mathrm{LEVEL}$ \\
\hline $03-08-1999$ & $01: 55: 26$ & 119.95 & 1.08021 \\
\hline $03-08-1999$ & $01: 58: 27$ & 107.95 & 1.08071 \\
\hline $03-08-1999$ & $02: 01: 31$ & 95.95 & 1.08659 \\
\hline $03-08-1999$ & $02: 04: 32$ & 83.95 & $1.08241=$ MINUMUM DENSITY \\
\hline $03-08-1999$ & $02: 07: 33$ & 71.95 & 1.08599 \\
\hline $03-08-1999$ & $02: 10: 34$ & 59.95 & 1.08989 \\
\hline $03-08-1999$ & $02: 13: 35$ & 47.95 & 1.09292 \\
\hline $03-08-1999$ & $02: 16: 36$ & 35.95 & 1.09495 \\
\hline
\end{tabular}




\section{APPENDIX A}

\begin{tabular}{llll}
$03-08-1999$ & $02: 19: 37$ & 23.95 & 1.10413 \\
2 ET LEVEL DENSITY - MINIMUM $=0.000 \perp 4$ & \\
\multicolumn{5}{c}{} \\
Density Profile Start: & $03-08-1999$ & $03: 40: 50$ \\
Date & Time & LeVel & SpG \\
$================================$ \\
$03-08-1999$ & $03: 07: 26$ & 155.95 & 1.08148 \\
$03-08-1999$ & $03: 10: 27$ & 143.95 & 1.08199 \\
$03-08-1999$ & $03: 13: 28$ & 131.95 & $1.08075=2$ FT LEVEL \\
$03-08-1999$ & $03: 16: 29$ & 119.95 & 1.07894 \\
$03-08-1999$ & $03: 19: 30$ & 107.95 & 1.07849 \\
$03-08-1999$ & $03: 22: 34$ & 95.95 & $1.07734=$ MINUMUM DENSITY \\
$03-08-1999$ & $03: 25: 35$ & 83.95 & 1.08266 \\
$03-08-1999$ & $03: 28: 36$ & 71.95 & 1.09549 \\
$03-08-1999$ & $03: 31: 37$ & 59.95 & 1.09968 \\
$03-08-1999$ & $03: 34: 38$ & 47.95 & 1.10277 \\
$03-08-1999$ & $03: 37: 39$ & 35.95 & 1.10537 \\
$03-08-1999$ & $03: 40: 40$ & 23.95 & 1.11381
\end{tabular}

2 F'T LEVEL DENSITY - MINIMUM $=0.00341$

\begin{tabular}{|c|c|c|c|}
\hline \multicolumn{2}{|c|}{ Density Profile start: } & $03-08-1999$ & $18: 54: 10$ \\
\hline \multicolumn{4}{|c|}{ 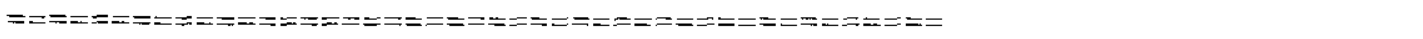 } \\
\hline $03-08-1999$ & $18: 22: 58$ & 146.47 & 1.08631 \\
\hline $03-08-1999$ & $18: 25: 59$ & 134.47 & $1.08484=$ MINUMUM LENSITY \\
\hline $03-08-1999$ & $18: 29: 00$ & 122.47 & $1.085=2 \mathrm{ET}$ LEVEL \\
\hline $03-08-1999$ & $18: 32: 01$ & 110.47 & 1.08624 \\
\hline $03-08-1999$ & $18: 35: 02$ & 98.47 & 1.0862 \\
\hline $03-08-1999$ & $18: 38: 03$ & 86.47 & 1.0883 \\
\hline $03-08-1999$ & $18: 41: 04$ & 74.47 & 1.08532 \\
\hline $03-08-1999$ & $18: 44: 05$ & 62.47 & 1.08536 \\
\hline $03-08-1999$ & $18: 47: 06$ & 50.47 & 1.08575 \\
\hline $03-08-1999$ & $18: 50: 07$ & 38.47 & 1.0846 \\
\hline
\end{tabular}

2 FT LEVEL DENSITY - MINIMUM $=0.00016$

\begin{tabular}{|c|c|c|c|}
\hline Density Pro & Le start: & $03-08-1999$ & $19: 31: 31$ \\
\hline Date & Time & Level & $\operatorname{spg}$ \\
\hline 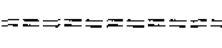 & $=:== \pm== \pm==$ & $======ニ z= \pm==$ & $===$ \\
\hline $03-08-1999$ & $19: 00: 37$ & 146.47 & 1.08522 \\
\hline $03-08-1999$ & $19: 03: 38$ & 134.47 & $1.08395=$ MINUMUM DENSITY \\
\hline $03-08-1999$ & $19: 06: 39$ & 122.47 & $1.08407=2 \mathrm{FT}$ LEVEL \\
\hline $03-08-1999$ & $19: 09: 40$ & 120.47 & 1.08596 \\
\hline $03-08-1999$ & $19: 12: 41$ & 98.47 & 1.08672 \\
\hline $03-08-1999$ & $19: 15: 42$ & 86.47 & 1.08840 \\
\hline $03-08-1999$ & $19: 18: 43$ & 74.47 & 1.08511 \\
\hline $03-08-1999$ & $19: 21: 44$ & 62.47 & 1.08486 \\
\hline
\end{tabular}




\section{APPENDIX A}

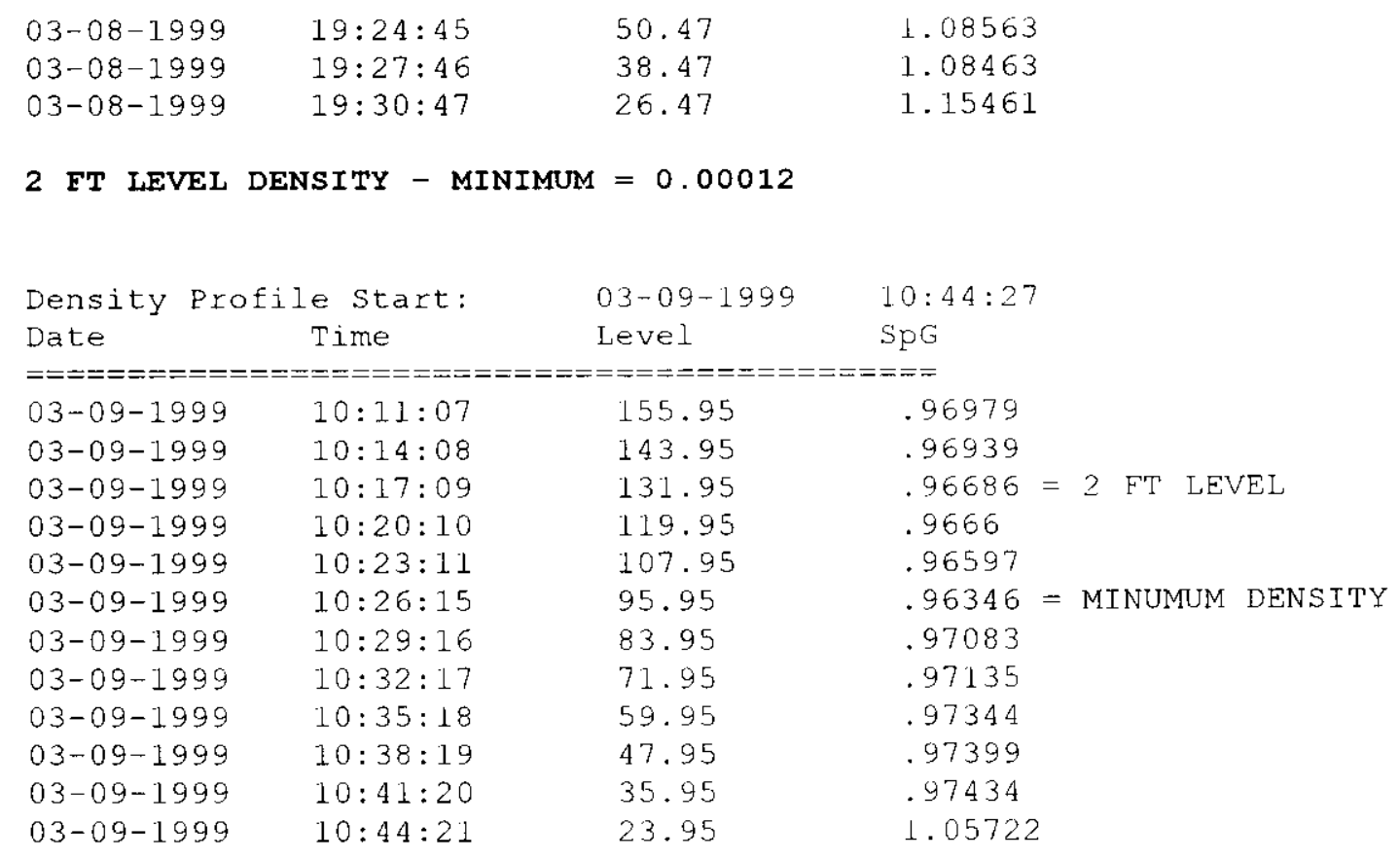

NOT INCLUDED IN CALCULATION DUE TO BELOW 1.0 VALUES

\begin{tabular}{|c|c|c|c|}
\hline \multicolumn{2}{|c|}{ Density Profile start: } & $03-09-1999$ & $14: 24: 10$ \\
\hline Date & Time & Level & SpG \\
\hline \multicolumn{4}{|c|}{ 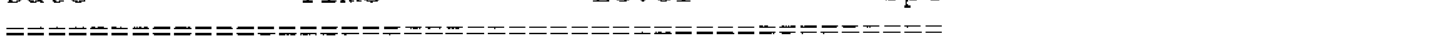 } \\
\hline $03-09-1999$ & $13: 50: 46$ & 155.95 & 1.07307 \\
\hline $03-09-1999$ & $13: 53: 47$ & 143.95 & 1.07279 \\
\hline $03-09-1999$ & $13: 56: 48$ & 131.95 & $1.0708=2 \mathrm{FT} \mathrm{LEVEL}$ \\
\hline $03-09-1999$ & $13: 59: 49$ & 119.95 & 1.06766 \\
\hline $03-09-1999$ & $14: 02: 50$ & 107.95 & 1.06764 \\
\hline $03-09-1999$ & $14: 05: 54$ & 95.95 & $1.06554=$ MINUMUM DENSITY \\
\hline $03-09-1999$ & $14: 08: 55$ & 83.95 & 1.0707 \\
\hline $03-09-1999$ & $14: 11: 56$ & 71.95 & 1.07175 \\
\hline $03-09-1999$ & $14: 14: 57$ & 59.95 & 1.07428 \\
\hline $03-09-1999$ & $14: 17: 58$ & 47.95 & 1.0752 \\
\hline $03-09-1999$ & $14: 20: 59$ & 35.95 & 1.0762 \\
\hline $03-09-1999$ & $14: 24: 00$ & 23.95 & 1.15992 \\
\hline \multicolumn{4}{|c|}{2 FT LEVEL DENSITY - MINIMUM $=0.00526$} \\
\hline Density Pro & le Start: & $03-09-1999$ & $17: 59: 02$ \\
\hline Date & Time & Level & $\operatorname{SpG}$ \\
\hline \multicolumn{4}{|c|}{ 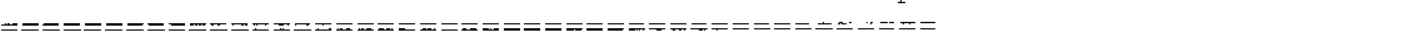 } \\
\hline $03-09-1999$ & $17: 25: 38$ & 155.95 & 1.07236 \\
\hline $03-09-1999$ & $17: 28: 39$ & 143.95 & 1.07099 \\
\hline $03-09-1999$ & $17: 31: 40$ & 131.95 & $1.0685=2$ F' LEVEL \\
\hline $03-09-1999$ & $17: 34: 41$ & 119.95 & 1.0676 \\
\hline
\end{tabular}




\section{APPENDIX A}

$\begin{array}{llll}03-09-1999 & 17: 37: 42 & 107.95 & 1.06625 \\ 03-09-1999 & 17: 40: 46 & 95.95 & 1.06377 \\ 03-09-1999 & 17: 43: 47 & 83.95 & 1.07095 \\ 03-09-1999 & 17: 46: 48 & 71.95 & 1.07131 \\ 03-09-1999 & 17: 49: 49 & 59.95 & 1.07341 \\ 03-09-1999 & 17: 52: 50 & 47.95 & 1.07433 \\ 03-09-1999 & 17: 55: 51 & 35.95 & 1.07496 \\ 03-09-1999 & 17: 58: 52 & 23.95 & 1.16089\end{array}$

2 FT LEVEL DENSITY - MINIMUM $=0.00473$

\begin{tabular}{|c|c|c|c|}
\hline \multicolumn{2}{|c|}{ Density Profile Start: } & \multirow{2}{*}{$\begin{array}{l}\text { 03-09-1999 } \\
\text { Level }\end{array}$} & $19: 23: 22$ \\
\hline Date & Time & & \\
\hline \multicolumn{4}{|c|}{ 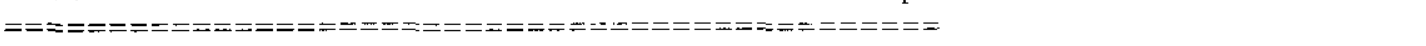 } \\
\hline $03-09-1999$ & $18: 49: 40$ & 155.95 & 1.08304 \\
\hline $03-09-1999$ & $18: 52: 41$ & 143.95 & 1.0825 \\
\hline $03-09-1999$ & $18: 55: 42$ & 131.95 & $1.08085=2 \mathrm{FT}$ LEVEL \\
\hline $03-09-1999$ & $18: 58: 43$ & 119.95 & 1.0783 \\
\hline $03-09-1999$ & $19: 01: 44$ & 107.95 & 1.07709 \\
\hline $03-09-1999$ & $19: 04: 48$ & 95.95 & $1.07617=$ MINUMUM DENSITY \\
\hline $03-09-1999$ & $19: 07: 49$ & 83.95 & 1.08146 \\
\hline $03-09-1999$ & $19: 10: 50$ & 71.95 & 1.08271 \\
\hline $03-09-1999$ & $19: 13: 51$ & 59.95 & 1.08482 \\
\hline 03-09-1999 & $19: 16: 52$ & 47.95 & 1.08685 \\
\hline $03-09-1999$ & $19: 19: 53$ & 35.95 & 1.08683 \\
\hline 03-09-1999 & $19: 22: 54$ & 23.95 & 1.17554 \\
\hline
\end{tabular}

2 ET LEVEL DENSITY - MINIMUM $=0.00468$

\begin{tabular}{|c|c|c|c|c|}
\hline Density Pro & e start: & $03-10-1999$ & $10: 14: 44$ & \\
\hline Date & Time & Level & SpG & \\
\hline$==:=====-= \pm=$ & $======== \pm$ & $======-===$ & $==$ & \\
\hline $03-10-1999$ & $09: 41: 16$ & 155.95 & 1.07903 & \\
\hline $03-10-1999$ & $09: 44: 17$ & 143.95 & 1.07884 & \\
\hline $03-10-1999$ & $09: 47: 18$ & 131.95 & 1.07662 & $=2 \mathrm{FT}$ LEVEL \\
\hline $03-10-1999$ & $09: 50: 19$ & 119.95 & 1.07477 & \\
\hline $03-10-1999$ & $09: 53: 20$ & 107.95 & 1.07413 & \\
\hline $03-10-1999$ & $09: 56: 24$ & 95.95 & 1.07123 & 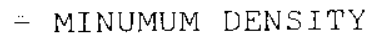 \\
\hline $03-10-1999$ & $09: 59: 25$ & 83.95 & 1.07696 & \\
\hline $03-10-1999$ & $10: 02: 26$ & 71.95 & 1.07878 & \\
\hline $03-10-1999$ & $10: 05: 27$ & 59.95 & 1.08076 & \\
\hline $03-10-1999$ & $10: 08: 28$ & 47.95 & 1.08307 & \\
\hline $03-10-1999$ & $10: 11: 29$ & 35.95 & 1.08279 & \\
\hline $03-10-1999$ & $10: 14: 30$ & 23.95 & 1.17494 & \\
\hline
\end{tabular}

2 ET LEVEL DENSITY - MINIMUM $=0.00539$

$\begin{array}{lcll}\text { Density } & \text { Profile Start: } & 03-10-1999 & 10: 54: 14 \\ \text { Date } & \text { Time } & \text { Level } & \text { SpG }\end{array}$




\section{APPENDIX A}

\begin{tabular}{|c|c|c|c|}
\hline $03-10-1999$ & $10: 20: 52$ & 155.95 & 1.07871 \\
\hline $03-10-1999$ & $10: 23: 53$ & 143.95 & 1.07864 \\
\hline $03-10-1999$ & $10: 26: 54$ & 131.95 & $1.07705=2 \mathrm{FT}$ LEVEL \\
\hline $03-10-1999$ & $10: 29: 55$ & 119.95 & 1.07499 \\
\hline $03-10-1999$ & $10: 32: 56$ & 107.95 & 1.07463 \\
\hline $03-10-1999$ & $10: 36: 00$ & 95.95 & $1.07161=$ MINUMUM DENSITY \\
\hline $03-10-1999$ & $10: 39: 01$ & 83.95 & 1.07736 \\
\hline $03-10-1999$ & $10: 42: 02$ & 71.95 & 1.07837 \\
\hline $03-10-1999$ & $10: 45: 03$ & 59.95 & 1.08091 \\
\hline $03-10-1999$ & $10: 48: 04$ & 47.95 & 1.08256 \\
\hline $03-10-1999$ & $10: 51: 05$ & 35.95 & 1.08318 \\
\hline $03-10-1999$ & $10: 54: 06$ & 23.95 & 1.1736 \\
\hline
\end{tabular}

2 FT LEVEL DENSITY - MINIMUM $=0.00544$

\begin{tabular}{|c|c|c|c|c|}
\hline Density Pro & le start: & $03-10-1999$ & $18: 22: 53$ & \\
\hline Date & $\begin{array}{l}\text { Time } \\
=======\end{array}$ & Level & $\mathrm{SpG}$ & \\
\hline $\begin{array}{l}==-===== \\
03-10-1999\end{array}$ & $\begin{array}{l}======== \\
17: 49: 28\end{array}$ & $\begin{array}{l}======= \\
155.95\end{array}$ & $\begin{array}{l}== \\
1.06848\end{array}$ & \\
\hline $03-10-1999$ & $17: 52: 29$ & 143.95 & 1.06799 & \\
\hline $03-10-1999$ & $17: 55: 30$ & 131.95 & 1.06587 & $=2 \mathrm{FT} \quad \mathrm{LEVEL}$ \\
\hline $03-10-1999$ & $17: 58: 31$ & 119.95 & 1.0633 & \\
\hline $03-10-1999$ & $18: 01: 32$ & 107.95 & $1.061 y^{\prime} \%$ & \\
\hline $03-10-1999$ & $18: 04: 36$ & 95.95 & 1.05907 & $=$ MINUMUM DENSITY \\
\hline $03-10-1999$ & $18: 07: 37$ & 83.95 & 1.06536 & \\
\hline $03-10-1999$ & $18: 10: 38$ & 71.95 & 1.06666 & \\
\hline $03-10-1999$ & $18: 13: 39$ & 59.95 & 1.06906 & \\
\hline $03-10-1999$ & $18: 16: 40$ & 47.95 & 1.07053 & \\
\hline $03-10-1999$ & $18: 19: 41$ & 35.95 & 1.07183 & \\
\hline $03-10-1999$ & $18: 22: 42$ & 23.95 & 1.16098 & \\
\hline 2 FT LEVEL & NSITY - MI & $\Lambda=0.00680$ & & \\
\hline Density Pro & le start: & $03-10-1999$ & $19: 11: 44$ & \\
\hline Date & Time & Level & $\operatorname{Spg}$ & \\
\hline$==\approx=====0=0$ & $====:=====$ & $== \pm=======$ & $= \pm==$ & \\
\hline $03-10-1999$ & $18: 38: 22$ & 155.95 & 1.06769 & \\
\hline $03-10-1999$ & $18: 41: 23$ & 143.95 & 1.0672 & \\
\hline $03-10-1999$ & $18: 44: 24$ & 131.95 & 1.06517 & $=2 \mathrm{FT}$ LEVEL \\
\hline $03-10-1999$ & $18: 47: 25$ & 119.95 & 1.06319 & \\
\hline $03-10-1999$ & $18: 50: 26$ & 107.95 & 1.06191 & \\
\hline $03-10-1999$ & $18: 53: 30$ & 95.95 & 1.05952 & $=$ MINUMUM DENSITY \\
\hline $03-10-1999$ & $18: 56: 31$ & 83.95 & 1.06506 & \\
\hline $03-10-1999$ & $18: 59: 32$ & 71.95 & $1.066 \%$ & \\
\hline $03-10-1999$ & $19: 02: 33$ & 59.95 & 1.06884 & \\
\hline $03-10-1999$ & $19: 05: 34$ & 47.95 & 1.07023 & \\
\hline $03-10-1999$ & $19: 08: 35$ & 35.95 & 1.07166 & \\
\hline $03-10-1999$ & $19: 11: 36$ & 23.95 & 1.15958 & \\
\hline
\end{tabular}




\section{APPENDIX A}

2 FT LEVEI DENSITY - MINIMUM $=0.00565$

\begin{tabular}{|c|c|c|c|}
\hline \multicolumn{2}{|c|}{ Density Profile start: } & $03-11-1999$ & $10: 35: 19$ \\
\hline Date & Time & Level & SpG \\
\hline \multicolumn{4}{|c|}{ 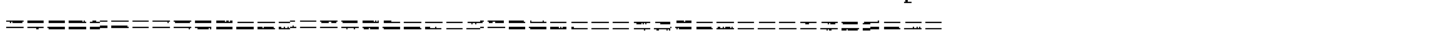 } \\
\hline $03-11-1999$ & $10: 01: 44$ & 155.95 & 1.06403 \\
\hline $03-11-1999$ & $10: 04: 45$ & 143.95 & 1.06441 \\
\hline $03-11-1999$ & $10: 07: 46$ & 131.95 & $1.06243=2$ FT LEVEL \\
\hline $03-11-1999$ & $10: 10: 47$ & 119.95 & 1.06059 \\
\hline $03-11-1999$ & $10: 13: 48$ & 107.95 & 1.05926 \\
\hline $03-11-1999$ & $10: 16: 52$ & 95.95 & $1.05687=$ MINUMUM DENSITY \\
\hline $03-11-1999$ & $10: 19: 53$ & 83.95 & 1.06258 \\
\hline $03-11-1999$ & $10: 22: 54$ & 71.95 & 1.06314 \\
\hline $03-11-1999$ & $10: 25: 55$ & 59.95 & 1.06562 \\
\hline $03-11-1999$ & $10: 28: 56$ & 47.95 & 1.06681 \\
\hline $03-11-1999$ & $10: 31: 57$ & 35.95 & 1.06758 \\
\hline $03-11-1999$ & $10: 34: 58$ & 23.95 & 1.14553 \\
\hline
\end{tabular}

2 ET LEVEL DENSITY - MINIMUM $=0.00556$

$\begin{array}{llll}\begin{array}{l}\text { Density Profile Start: } \\ \text { Date }\end{array} & \begin{array}{l}03-11-1999 \\ \text { Time }\end{array} & \begin{array}{l}1 \perp: 14: 47 \\ \text { Level }\end{array} \\ ================================== \\ 03-11-1999 & 10: 41: 29 & 155.95 & 1.06365 \\ 03-11-1999 & 10: 44: 30 & 143.95 & 1.06347 \\ 03-11-1999 & 10: 47: 31 & 131.95 & 1.06247=2 \text { FT LEVEL } \\ 03-11-1999 & 10: 50: 32 & 119.95 & 1.06018 \\ 03-11-1999 & 10: 53: 33 & 107.95 & 1.05919 \\ 03-11-1999 & 10: 56: 37 & 95.95 & 1.0573=\text { MINUMUM DENSITY } \\ 03-11-1999 & 10: 59: 38 & 83.95 & 1.0623 \\ 03-11-1999 & 11: 02: 39 & 71.95 & 1.06339 \\ 03-11-1999 & 11: 05: 40 & 59.95 & 1.06562 \\ 03-11-1999 & 11: 08: 41 & 47.95 & 1.06687 \\ 03-11-1999 & 11: 11: 42 & 35.95 & 1.06778 \\ 03-11-1999 & 11: 14: 43 & 23.95 & 1.14569\end{array}$

2 FT LEVEL DENSITY - MINIMUM $=0.00517$

$\begin{array}{llll}\begin{array}{l}\text { Density Profile Start: } \\ \text { Date }\end{array} & \begin{array}{l}03-18-1999 \\ \text { Time }\end{array} & \begin{array}{l}14: 08: 27 \\ \text { Level }\end{array} & \text { SpG } \\ ==================================== \\ 03-18-1999 & 13: 37: 52 & 155.95 & 1.07689 \\ 03-18-1999 & 13: 40: 53 & 143.95 & 1.07602 \\ 03-18-1999 & 13: 43: 54 & 131.95 & 1.07463=2 \text { ET LEVEL } \\ 03-18-1999 & 13: 46: 55 & 119.95 & 1.07227 \\ 03-18-1999 & 13: 49: 56 & 107.95 & 1.07059 \\ 03-18-1999 & 13: 53: 00 & 95.95 & 1.06908=\text { MINUMUM DENSITY } \\ 03-18-1999 & 13: 56: 01 & 83.95 & 1.07314 \\ 03-18-1999 & 13: 59: 02 & 71.95 & 1.07423\end{array}$




\section{APPENDIX A}

$\begin{array}{llll}03-18-1999 & 14: 02: 03 & 59.95 & 1.07642 \\ 03-18-1999 & 14: 05: 04 & 47.95 & 1.07768 \\ 03-18-1999 & 14: 08: 05 & 35.95 & 1.07912 \\ & & \end{array}$


DISTRIBUTION SHEET

\begin{tabular}{|c|c|c|c|c|c|}
\hline \multirow{2}{*}{$\begin{array}{l}\text { To } \\
\text { Distribution }\end{array}$} & \multirow{2}{*}{\multicolumn{3}{|c|}{ Process Control }} & \multicolumn{2}{|c|}{ Page 1 of 1} \\
\hline & & & & \multicolumn{2}{|c|}{$04 / 21 / 99$} \\
\hline \multicolumn{4}{|c|}{ Project Title/Work Order } & \multicolumn{2}{|c|}{ EDT No. EDT-611462 } \\
\hline \multicolumn{4}{|c|}{$\begin{array}{l}\text { HNF-4379, Rev. 0, "Waste Retrieval Sluicing System Campaign } \\
\text { Number } 1 \text { Solids Volume Transferred Calculation" }\end{array}$} & \multicolumn{2}{|c|}{ ECN No. N/A } \\
\hline Name & MSIN & $\begin{array}{c}\text { Text } \\
\text { with } \\
\text { All } \\
\text { Attach. }\end{array}$ & Text 0nly & $\begin{array}{l}\text { Attach./ } \\
\text { Appendix } \\
\text { Only }\end{array}$ & $\begin{array}{l}\mathrm{EDT} / \mathrm{ECN} \\
\text { Only }\end{array}$ \\
\hline
\end{tabular}

U. S. Department of Energy -

Richland Field office

W. AbduT

DOE/RL Reading Room

S7-54 X

H2-53 $\quad X$

COGEMA

J. R. Bellomy

S5-05 $\quad X$

Lockheed Mart in Hanford Corp.

K. J. Anderson

D. G. Baide

S5-04 $\quad x$

W. E. Bryan

K. G. Carothers

S5-05

S5-05

R2-11

S5-07

G. N. Hanson

R2- 11

R2-11

L. A. Stauffer

R1-10

$x$

T.C.S.R.C.

Lockheed Mart in Services, Inc.

Central Files

B1-07 $\quad X$

Los Alamos Technical Associates

J. M. Jones

S5-05 $\quad X$

MacTec

J. C. Guyette

$57-40 \quad X$

Numatec Hanford Corporation

J. W. Bailey

J. W. Lentsch

S5-05 $\quad x$

S5-07 $X$

